\title{
Visible-Light Photoinitiation of (Meth)acrylate Polymerization with Autonomous Post-
}

\section{Conversion}

Kangmin Kim, ${ }^{1}$ Jasmine Sinha, ${ }^{2}$ Jeffrey W. Stansbury ${ }^{2,3, *}$ Charles B. Musgrave, ${ }^{1,2,4,5, *}$

${ }^{1}$ Department of Chemistry, University of Colorado, Boulder, Colorado, USA

${ }^{2}$ Department of Chemical and Biological Engineering, University of Colorado, Boulder, Colorado, USA

${ }^{3}$ Department of Craniofacial Biology, School of Dental Medicine, Aurora, Colorado, USA

${ }^{4}$ Materials Science and Engineering, University of Colorado, Boulder, CO

${ }^{5}$ Renewable and Sustainable Energy Institute, University of Colorado, Boulder, CO

\section{Supplementary Information}

\section{Contents}

1. Instrumental Methods and Materials ...................................... 2

2. Synthesis of visible photobase generator..........................S3-S6

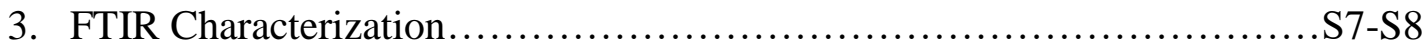

4. Molar Absorptivity................................................S8

5. Resonance Structures............................................. 9

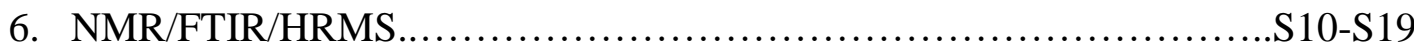

7. Effect of 6-bromo substitution..................................... 19

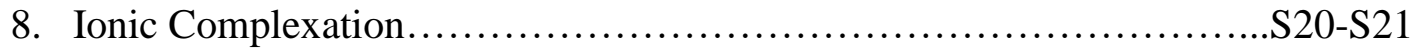

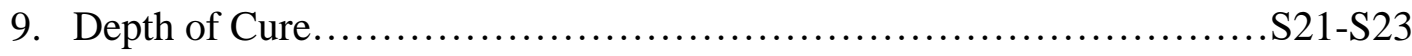

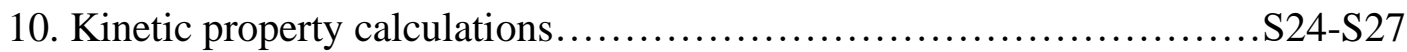

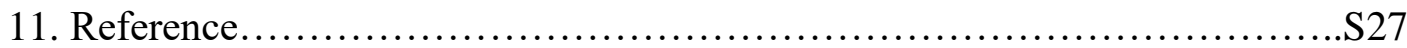




\section{INSTRUMENTAL METHODS AND MATERIALS}

\section{NMR Spectroscopy and HRMS}

${ }^{1} \mathrm{H}-\mathrm{NMR}$ and ${ }^{13} \mathrm{C}-\mathrm{NMR}$ spectra were recorded on a Bruker $400 \mathrm{MHz}$ NMR spectrometer. Proton chemical shifts are expressed in parts per million $(\delta)$ using TMS as an internal standard. The $\delta$ scale was referenced to deuterated solvents, as indicated in the respective measurement. For quantitative NMR, ethylene carbonate was used as an internal standard. HRMS analysis was performed on a Waters Synapt G2 HDMS Q-TOF Mass Spectrometer.

\section{UV-Vis Spectroscopy}

The UV-Vis spectra of photoinitiators in dimethylformamide were recorded in PMMA cuvettes with $1 \mathrm{~cm}$ optical path lengths in a UV-Vis spectrophotometer (Thermo-Fischer Scientific) after baseline correction with a blank run.

Materials 2,4-Dimethoxy-6-hydroxybenzaldehyde, ethyl (4-methylbenzoyl)acetate, Nbromosuccinimide (NBS), benzoyl peroxide (BPO), anhydrous toluene, and dichloromethane were purchased from Sigma Aldrich. Chlorobenzene, 4-dimethylaminotoluene (DMPT), and sodium tetraphenylborate were purchased from Alfa Aesar. NBS was purified by recrystallization from water, $\mathrm{BPO}$ was purified by dissolving it in dichloromethane and recrystallizing from methanol. All amines were purchased in the highest purity available and other chemicals were of reagent grade and used without further purification. Triethylene glycol dimethacrylate (TEGDMA, 95\%) and $\alpha$-methylene- $\gamma$-butyrolactone (MBL, 95\%) were purchased from TCI America with $60 \mathrm{ppm}$ MEHQ. 


\section{SYNTHESIS OF VISIBLE PHOTOBASE GENERATOR}

Synthesis of 5,7-dimethoxy-6-bromo-3-aroylcoumarine-DMPT/BPh 4 synthesis

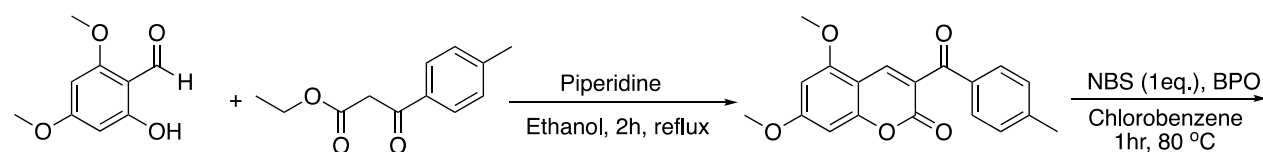

(1)

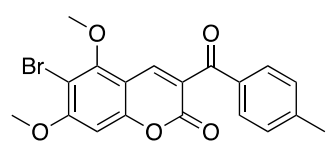

(2) NBS (2eq.), BPO Chlorobenzene $4 \mathrm{hr}, 80^{\circ} \mathrm{C}$

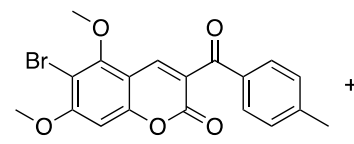

(2)

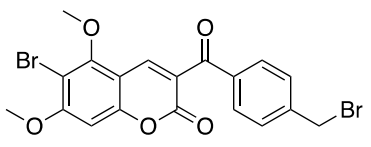

(3)

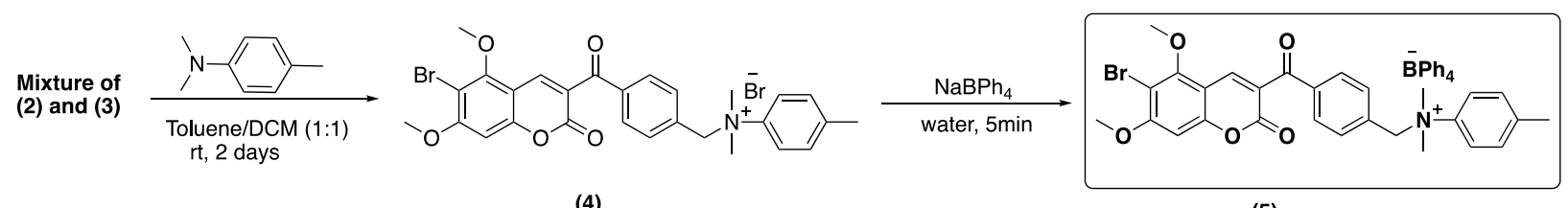

(4)

(5)

\section{a. Synthesis of 5,7-dimethoxy-3-aroylcoumarin (1)}

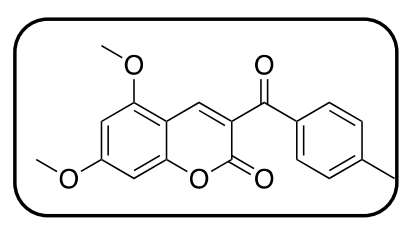

$0.5 \mathrm{~mL}$ of piperidine was added to the solution of $1 \mathrm{~g}(5.4 \mathrm{mmol})$ of 2,4-dimethoxy-6hydroxybenzaldehyde and $1.13 \mathrm{~g}(5.4 \mathrm{mmol})$ of ethyl (4-methylbenzoyl)acetate in $40 \mathrm{~mL}$ of ethanol and kept under reflux for $2 \mathrm{hr}$. Following refluxing, the reaction mixture was cooled, and the product obtained by filtering and washing with cold ethanol. The white solid product was then dried under vacuum. Yield: 98\%; ${ }^{1} \mathrm{H}$ NMR $\left(\mathrm{CDCl}_{3}, \delta \mathrm{ppm}\right): 8.45(\mathrm{~s}, 1 \mathrm{H}), 7.78\left(\mathrm{dd}, \mathrm{J}_{1}=8.15 \mathrm{~Hz}\right.$, $\left.\mathrm{J}_{2}=1.81 \mathrm{~Hz}, 2 \mathrm{H}\right), 7.30\left(\mathrm{dd}, \mathrm{J}_{1}=8.52 \mathrm{~Hz}, \mathrm{~J}_{2}=1.81 \mathrm{~Hz}, 2 \mathrm{H}\right), 6.49(\mathrm{~d}, \mathrm{~J}=2.15 \mathrm{~Hz}, 1 \mathrm{H}), 6.33(\mathrm{~d}, \mathrm{~J}=$ $2.16 \mathrm{~Hz}, 1 \mathrm{H}), 3.92(\mathrm{~s}, 6 \mathrm{H}), 2.45(\mathrm{~s}, 3 \mathrm{H}) .{ }^{13} \mathrm{C} \mathrm{NMR}\left(\mathrm{CDCl}_{3}, \delta \mathrm{ppm}\right): 191.81,165.74,159.09,158.27$ $157.85,144.18,142.02,134.43,129.72,129.15,120.65,103.67,95.10,92.80,56.14,56.06,21.79$. 
IR (KBr, cm $\left.{ }^{-1}\right): 3027,2979,2947,1937,1723,1657,1606,1571,1498,1468,1422,1369,1312$, 1240, 1178, 1114, 1049, 946, 914, 849, 822, 810, 787, 764. HRMS (ESI $\left.{ }^{+}\right) \mathrm{m} / \mathrm{z}$ calcd for $\mathrm{C}_{19} \mathrm{H}_{16} \mathrm{O}_{5}$ $[\mathrm{M}+\mathrm{H}]^{+}: 325.1076$, found: 325.1074 .

\section{b. Synthesis of bromo-tolyl-5,7-dimethoxy-6-bromo-3-aroylcoumarin (3)}

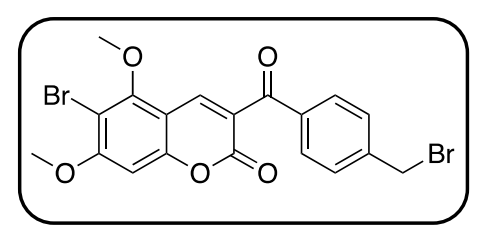

$1.5 \mathrm{~g}$ (4.6 mmol) of 1 was dissolved in chlorobenzene or chloroform at $70^{\circ} \mathrm{C}$, followed by the addition of $0.9 \mathrm{~g}(5 \mathrm{mmol})$ of $N$-bromosuccinimide and $0.11 \mathrm{~g}(0.45 \mathrm{mmol})$ of benzoyl peroxide while the mixture was continuously stirred at $70^{\circ} \mathrm{C}$ for $1 \mathrm{hr}$. The reaction mixture was then cooled, and the organic solvent evaporated. The yellow solid hence obtained was re-dissolved in dichloromethane and the organic layer was then washed with $\mathrm{NaHCO}_{3}$ followed by washing with brine and water. The combined organic layer was then dried over $\mathrm{Na}_{2} \mathrm{SO}_{4}$ and concentrated at reduced pressure to obtain a yellow solid. Yield: $50 \%{ }^{1} \mathrm{H} \mathrm{NMR}\left(\mathrm{CDCl}_{3}, \delta \mathrm{ppm}\right): 8.44(\mathrm{~s}, 1 \mathrm{H}), 7.78$ $\left(\mathrm{dd}, \mathrm{J}_{1}=8.15 \mathrm{~Hz}, \mathrm{~J}_{2}=1.6 \mathrm{~Hz}, 2 \mathrm{H}\right), 7.30\left(\mathrm{dd}, \mathrm{J}_{1}=8.54 \mathrm{~Hz}, \mathrm{~J}_{2}=1.15 \mathrm{~Hz}, 2 \mathrm{H}\right), 6.41(\mathrm{~s}, 1 \mathrm{H}), 4.07(\mathrm{~s}$, 3H), $4.00(\mathrm{~s}, 3 \mathrm{H}), 2.45$ (s, 3H). ${ }^{13} \mathrm{C} \mathrm{NMR}\left(\mathrm{CDCl}_{3}, \delta \mathrm{ppm}\right): 191.43,161.47,158.18,157.72,153.66$, $144.46,141.42,134.11,129.80,129.18,121.73,104.34,91.14,56.92,56.30,21.83 . \mathrm{IR}\left(\mathrm{KBr}, \mathrm{cm}^{-}\right.$ $\left.{ }^{1}\right): 3121,3025,2953,1721,1659,1608,1486,1475,1443,1424,1337,1238,1181,1116,1100$, 992, 948, 925, 840, 790, 769, 684 (C-Br stretching). HRMS (ESI $\left.{ }^{+}\right)$m/z calcd for $\mathrm{C}_{19} \mathrm{H}_{15} \mathrm{BrO}_{5}[\mathrm{M}-$ $\mathrm{H}]^{+}:$403.0181, found: 403.0188.

$1 \mathrm{~g}(2.4 \mathrm{mmol})$ of 2 was dissolved in chlorobenzene at $80^{\circ} \mathrm{C}$, followed by addition of $0.88 \mathrm{~g}(4.9$ mmol) of $N$-bromosuccinimide and $0.06 \mathrm{~g}(0.24 \mathrm{mmol})$ of benzoyl peroxide while being continuously stirred at $80^{\circ} \mathrm{C}$ for $4 \mathrm{hr}$. After $4 \mathrm{hr}$, the reaction mixture was cooled, and the organic 
solvent evaporated. The yellow solid hence obtained was then re-dissolved in dichloromethane and the organic layer was then washed with $\mathrm{NaHCO}_{3}$ followed by washing with brine and water. The combined organic layer was then dried over $\mathrm{Na}_{2} \mathrm{SO}_{4}$ and concentrated at reduced pressure to obtain a yellow solid, a mixture of $\mathbf{2}$ and $\mathbf{3}(50 \%$ yield). The presence of compound $\mathbf{3}$ was confirmed 1H NMR and HRMS. IR $\left(\mathrm{KBr}, \mathrm{cm}^{-1}\right): 3117,3020,2992,2951,1721,1661,1613,1592,1470,1445$, 1339, 1236, 1181, 1114, 990, 946, 843, 787, 688 (C-Br stretching). HRMS $\left(\mathrm{ESI}^{+}\right) \mathrm{m} / \mathrm{z}$ calcd for $\mathrm{C}_{19} \mathrm{H}_{14} \mathrm{Br}_{2} \mathrm{O}_{5}[\mathrm{M}+\mathrm{Na}]^{+}:$505.1240, found: 504.9090

\section{c. Synthesis of ARC-5,7-diOMe-6-Br-DMPT/BPh 4 (5)}

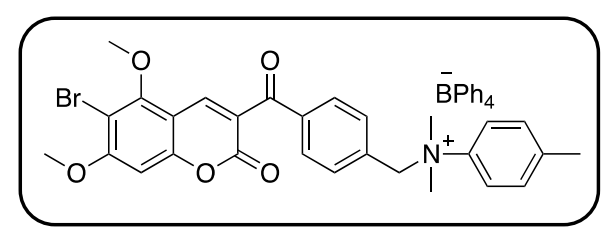

$0.55 \mathrm{~g}(4.1 \mathrm{mmol})$ of dimethyl-p-toluidine was added to a solution of $1.5 \mathrm{~g}(3.7 \mathrm{mmol})$ of mixture 2 and 3 in anhydrous toluene and dichloromethane (1:1) at room temperature under nitrogen atmosphere. The reaction mixture was then stirred for 2 days at room temperature. $24 \mathrm{hrs}$ after the addition of dimethyl-p-toluidine, a yellow precipitate was observed. The product was centrifuged to obtain the yellow precipitate, which was washed thrice with toluene followed by washing with hexane. The product was then dried under vacuum at $70{ }^{\circ} \mathrm{C}$ for $15 \mathrm{~min}$. The yellow solid hence obtained was the desired compound $\mathbf{4}$. The crude product $\mathbf{4}$ was directly used for next step without any purification. ${ }^{1} \mathrm{H}$ NMR (DMSO-d $6, \delta$ ppm): $8.28(\mathrm{~s}, 1 \mathrm{H}), 7.83(\mathrm{~d}, \mathrm{~J}=7.87 \mathrm{~Hz}, 2 \mathrm{H})$, $7.76(\mathrm{~d}, \mathrm{~J}=8.56 \mathrm{~Hz}, 2 \mathrm{H}), 7.43(\mathrm{~d}, \mathrm{~J}=8.56 \mathrm{~Hz}, 2 \mathrm{H}), 7.19(\mathrm{~d}, \mathrm{~J}=8.56 \mathrm{~Hz}, 2 \mathrm{H}), 6.82(\mathrm{~s}, 1 \mathrm{H}), 5.12$ (s, 2H), 4.07 (s, 3H), 4.02 (s, 3H), 3.59 (s, 6H), 2.38 (s, 3H). ${ }^{13} \mathrm{C}$ NMR (DMSO-d 6 , $\delta$ ppm): 191.66, $162.06,158.24,153.41,142.58,142.00,138.56,133.43,133.00,130.72,129.79,121.95,120.82$ 
104.20, 93.49, 89.48, 71.39, 57.99, 57.49, 55.41, 53.44, 20.79. IR (KBr, $\left.\mathrm{cm}^{-1}\right): 3119,3018,2951$, 1749, 1716, 1657, 1604, 1590, 1473, 1337, 1236 (C-N stretching), 1118, 1098, 992, 921, 843, 815, 790, 714, 693 (C-Br stretching). HRMS $\left(\mathrm{ESI}^{+}\right) \mathrm{m} / \mathrm{z}$ calcd for $\mathrm{C}_{28} \mathrm{H}_{27} \mathrm{Br}_{2} \mathrm{NO}_{5}[\mathrm{M}-\mathrm{Br}]^{+}: 538.1057$, found:538.1061.

To the solution of $0.9 \mathrm{~g}(1.6 \mathrm{mmol})$ of 4 in water was added a solution of $0.62 \mathrm{~g}(1.8 \mathrm{mmol})$ of sodium tetraphenyl borate in water dropwise at room temperature. The yellow turbidity was observed. The reaction was stirred for $5 \mathrm{~min}$ and then subjected to evaporation to obtain a yellow solid. The yellow solid was washed with water and then dried. The obtained solid was dissolved in acetonitrile and precipitated out in diethyl ether, which resulted in a pale yellow/yellow solid. The solid hence obtained was then dried under vacuum to produce the desired compound $\mathbf{5}$. Yield: $25 \%{ }^{1} \mathrm{H}$ NMR $\left(\mathrm{CD}_{3} \mathrm{CN}, \delta \mathrm{ppm}\right): 8.41(\mathrm{~s}, 1 \mathrm{H}), 7.76\left(\mathrm{dd}, \mathrm{J}_{1}=8.35 \mathrm{~Hz}, \mathrm{~J}_{2}=1.73 \mathrm{~Hz}, 2 \mathrm{H}\right), 7.52(\mathrm{dd}$, $\left.\mathrm{J}_{1}=8.84 \mathrm{~Hz}, \mathrm{~J}_{2}=2.2 \mathrm{~Hz}, 2 \mathrm{H}\right), 7.44\left(\mathrm{~d}, \mathrm{~J}_{1}=8.81 \mathrm{~Hz}, \mathrm{~J}_{2}=0.71 \mathrm{~Hz}, 2 \mathrm{H}\right), 7.29(\mathrm{~m}, 8 \mathrm{H}), 7.16\left(\mathrm{dd}, \mathrm{J}_{1}\right.$ $\left.=8.48 \mathrm{~Hz}, \mathrm{~J}_{2}=1.85 \mathrm{~Hz}, 2 \mathrm{H}\right), 7.02\left(\mathrm{~m}, \mathrm{~J}_{1}=7.83 \mathrm{~Hz}, \mathrm{~J}_{2}=7.32 \mathrm{~Hz}, 8 \mathrm{H}\right), 6.86\left(\mathrm{~m}, \mathrm{~J}_{1}=7.86 \mathrm{~Hz}, \mathrm{~J}_{2}=\right.$ $7.26 \mathrm{~Hz}, 4 \mathrm{H}), 6.67(\mathrm{~s}, 1 \mathrm{H}), 4.89(\mathrm{~s}, 2 \mathrm{H}), 4.08(\mathrm{~s}, 3 \mathrm{H}), 4.02(\mathrm{~s}, 3 \mathrm{H}), 3.52(\mathrm{~s}, 6 \mathrm{H})$, and $2.43(\mathrm{~s}, 3 \mathrm{H})$. ${ }^{13} \mathrm{C}$ NMR (DMSO-d $6, \delta$ ppm): 191.68, 164.54, 164.05, 163.56, 163.07, 162.07, 158.29, 158.26, $153.42,142.53,142.03,140.69,138.58,135.98,133.38,132.97,130.73,129.80,125.82,125.80$, $125.77,125.74,122.00,121.91,104.21,93.49,71.50,57.98,57.47,53.45,20.79 . \mathrm{IR}\left(\mathrm{KBr}, \mathrm{cm}^{-1}\right)$ : $3121,3059,2949,2836,1758,1716,1661,1611,1590,1473,1443,1365,1339,1307,1238$ (CN stretching), 1183, 1114, 1095, 997, 948, 843, 787, 744, 707, 682 (C-Br stretching). HRMS (ESI ${ }^{+}$) $\mathrm{m} / \mathrm{z}$ calcd for $\mathrm{C}_{52} \mathrm{H}_{47} \mathrm{BBrNO}_{5}[\mathrm{M}+\mathrm{Na}]^{+}: 880.2730$, found: 880.2617 . 


\section{FTIR Characterization}

Polymerization Kinetics: The conversion of vinyl functional groups of monomers by photopolymerization and dark-polymerization was monitored in real time with an FT-IR spectrophotometer (Nicolet Magna-IR Series II, Thermo Scientific, West Palm Beach, FL) by monitoring the peak area of the $=\mathrm{CH}_{2}$ overtone band at $6165 \mathrm{~cm}^{-1}$ in horizontal transmission mode. ${ }^{1}$ Irradiation was performed using a LED (ThorLabs) after 1 min of acquiring a baseline, and continued for 30-60 min. Unless otherwise specified, the light intensity was maintained at 50 $\mathrm{mW} / \mathrm{cm}^{2}$ for $455 \mathrm{~nm}$ irradiation, which was measured by a ThorLabs PM100D optical power meter with a S120VC photodiode power sensor (200 - $1100 \mathrm{~nm})$. In full-irradiation experiments, resins were continuously irradiated until the inflection point in the functional group conversion was observed, defined here as the vitrification conversion under ambient isothermal conditions, ${ }^{2}$ assuming the PI concentration remained sufficiently high to avoid becoming limiting. On the other hand, to demonstrate the dark-curing capability, partial cure studies were conducted for which the irradiation was terminated before the inflection point. Specifically, we identified the signal intensity at which the irradiation should terminate by calculating the percentage conversion from the initial total absorbance. For example, for a $20 \%$ partial cure, we stopped the irradiation at an absorbance of 4 , if the initial total absorbance was 5 , which thus signifies $20 \%$ conversion of the vinyl functional groups when irradiation was terminated. Additionally, factors that influence photopolymerization rates were chosen to perform partial cure studies, including concentrations, irradiation intensity, and the methacrylate resin system. In turn, such control permits the appropriate termination of irradiation to successfully investigate the dark-curing effect. For most of our studies, we elected to use a comonomer resin of TEGDMA and $\mathrm{MBL}^{3}$ to replicate a highly crosslinking polymer while ensuring solubility of our ionic photoinitiators. TEGDMA is a 
commonly used crosslink monomer and MBL is a non-fossil fuel-based monomer from a renewable feedstock that exhibits similar or better polymerization reactivity and materials properties than analogous methyl methacrylate. ${ }^{3-5}$ Samples were prepared by solubilizing BPO into TEGDMA and a photoinitiator into MBL, and then mixing the two solutions together. Prepared samples were kept at room temperature without an obvious change in appearance nor performance except occasional recrystallization of the photoinitiator, which was resolved by sonication. Circular laminated samples were prepared between glass slides with a $1.1 \mathrm{~mm}$ rubber gasket. The surface temperature of the glass slides was measured with an IR thermometer (Sper Scientific) to estimate the polymerization exotherm and resultant temperature change of the sample.

\section{Molar Absorptivity}

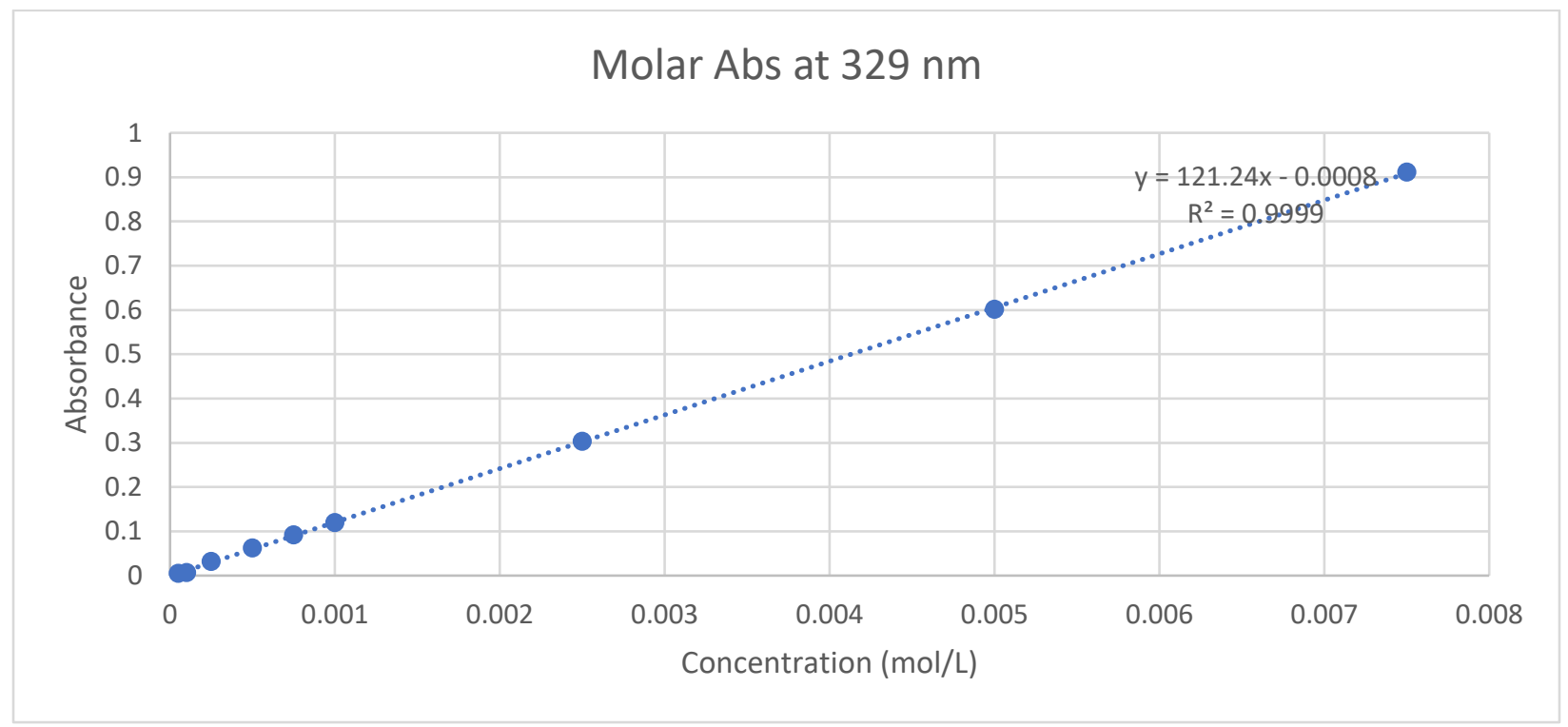

Figure S1. Concentration (mol/L) vs. absorbance plot to calculate molar absorptivity of BP-based dark curing photoinitiator at $329 \mathrm{~nm}$ in DMF $\left(\varepsilon=121.24 \mathrm{M}^{-1} \mathrm{~cm}^{-1}\right)$. 


\section{Resonance structures.}

(a)

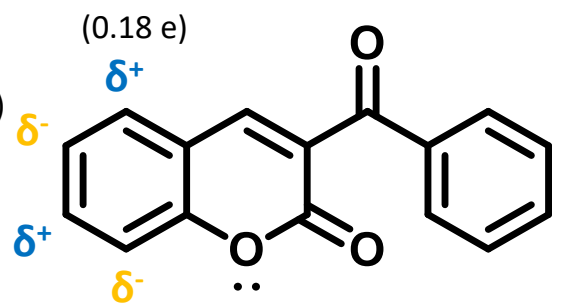

$(-0.21$ e)

\section{Cationic Resonance Structures}
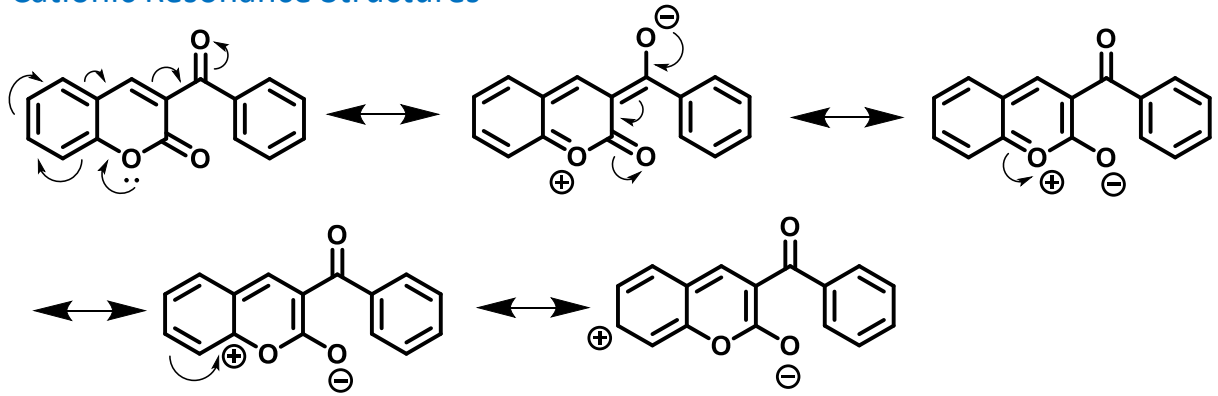

\section{Anionic Resonance Structures}
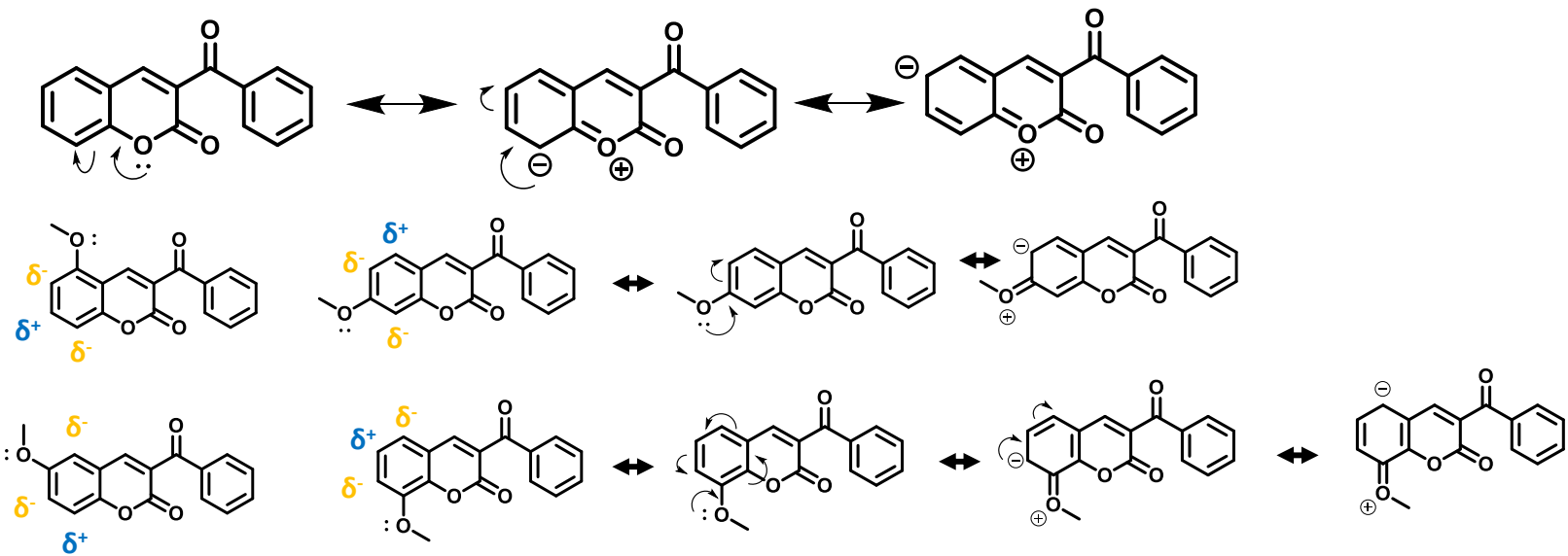

Figure S2. (a) Electron densities and resonance structures of ARC that were derived from lone pair electron movements. Cationic and anionic locations in the resonance structures allow visualization of electron-rich and -poor sites of ARC, which are confirmed by electron density calculations. (b) Electron-rich and -poor sites of methoxysubstituted ARC and their examples of electron movements. Note that 5- and 7- functionalization resulted in the natural pattern of resonance with ARC while 6- and 8- functionalization affect electron densities in the opposite way and reduce the overall resonance. 


\section{NMR/FTIR/HRMS data}

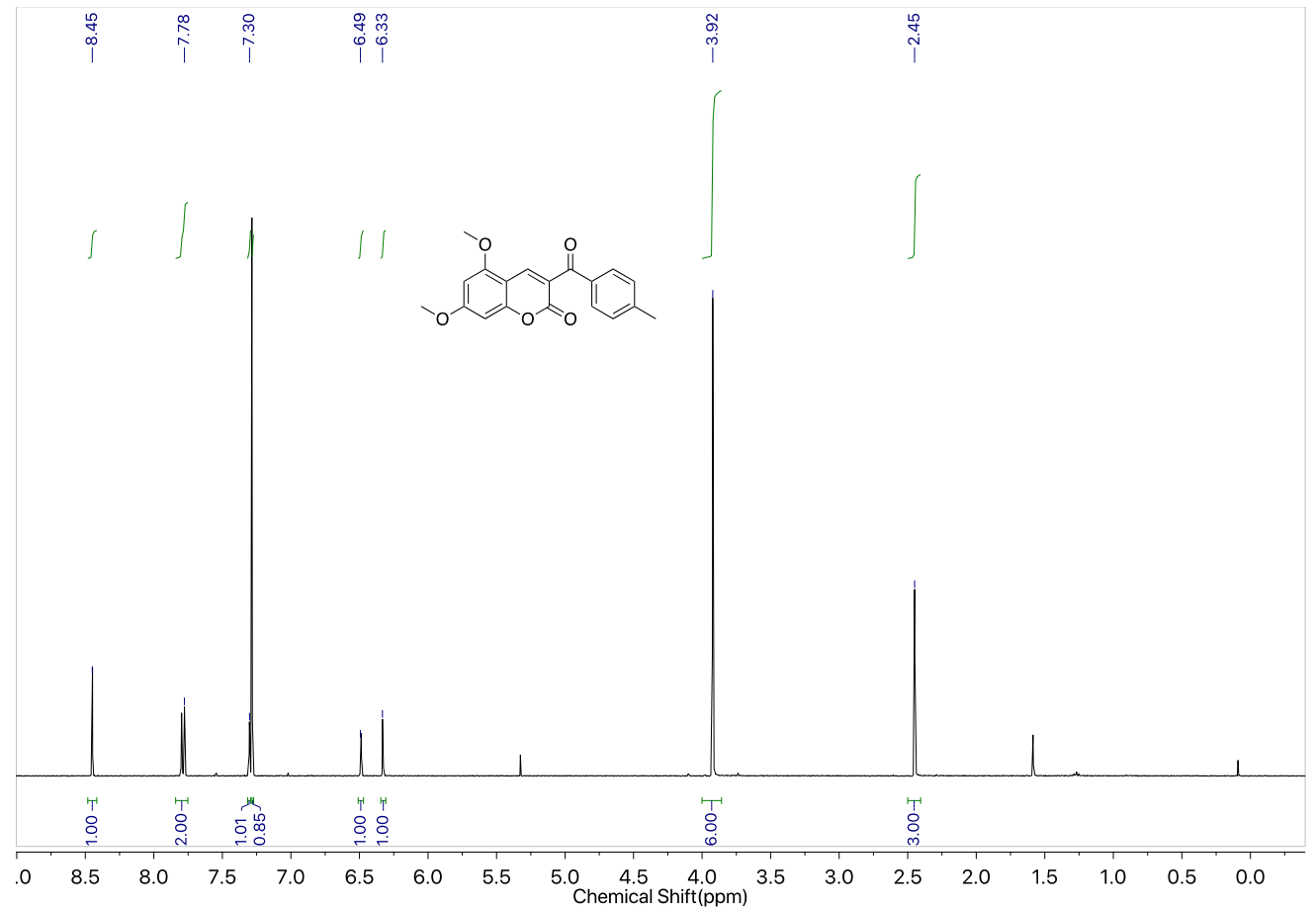

Figure S3. ${ }^{1} \mathrm{H}$ NMR of $\mathbf{1}$.

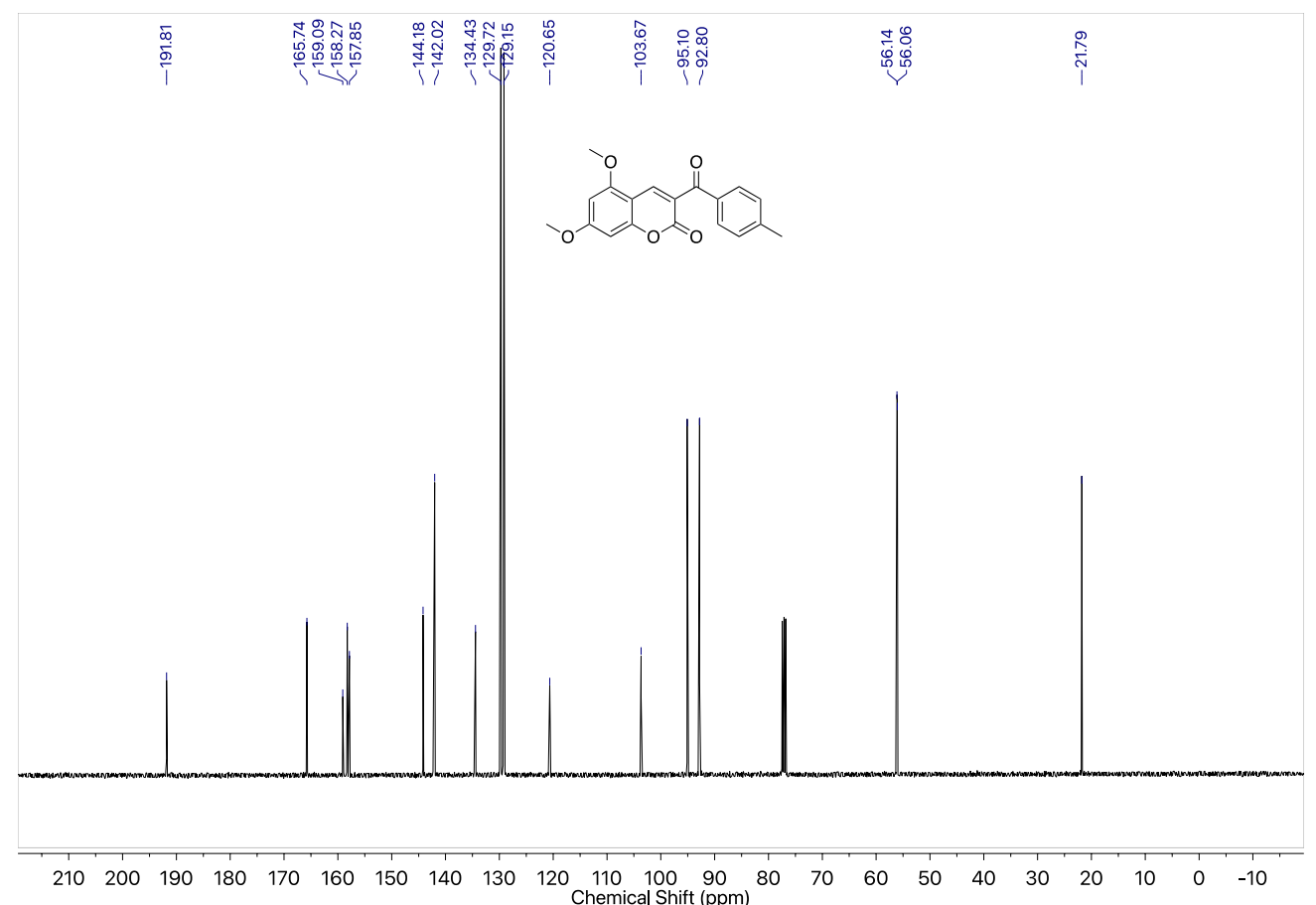

Figure S4. ${ }^{13} \mathrm{C}$ NMR of $\mathbf{1}$. 


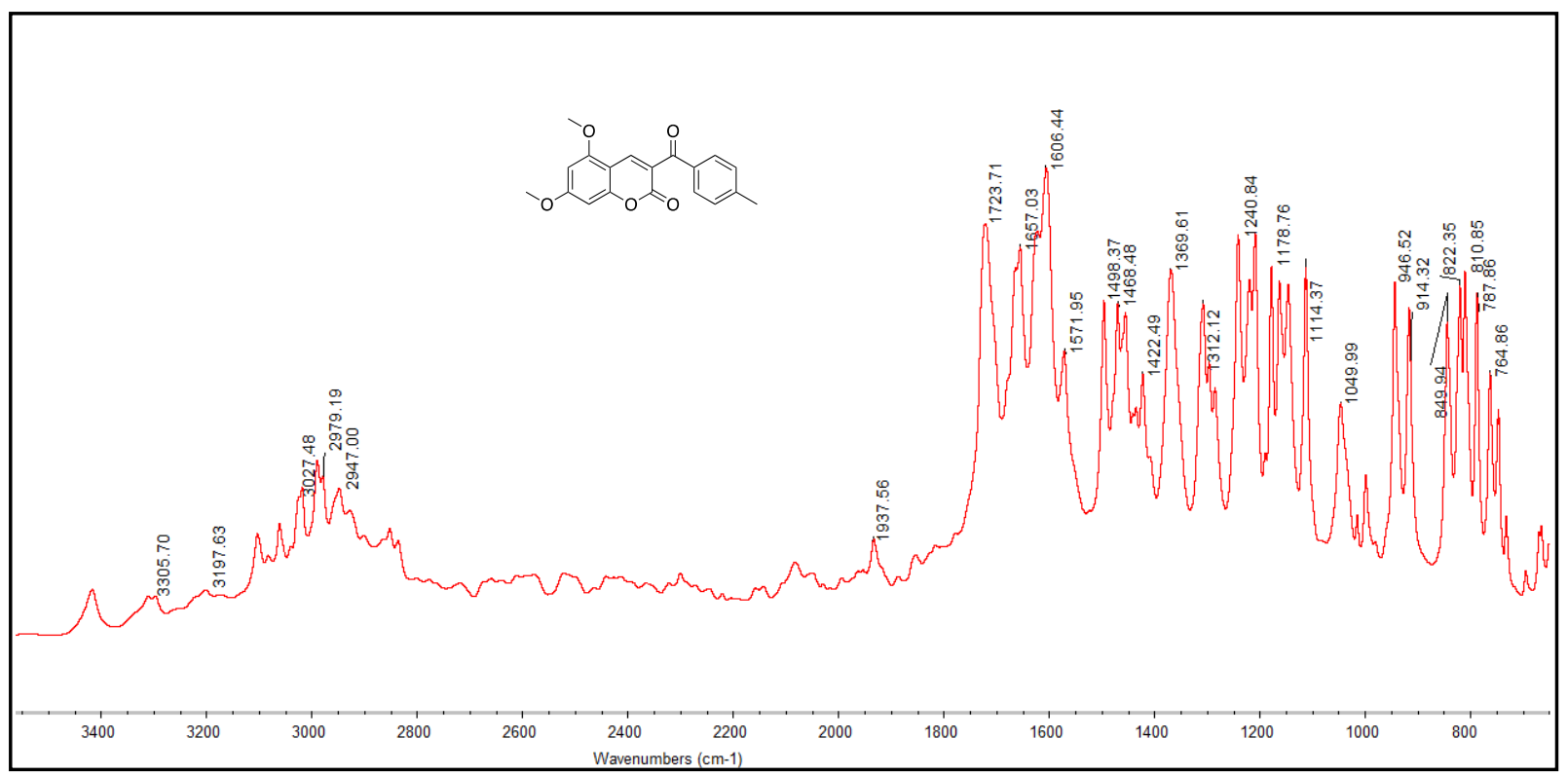

Figure S5. FTIR spectra of $\mathbf{1}$.
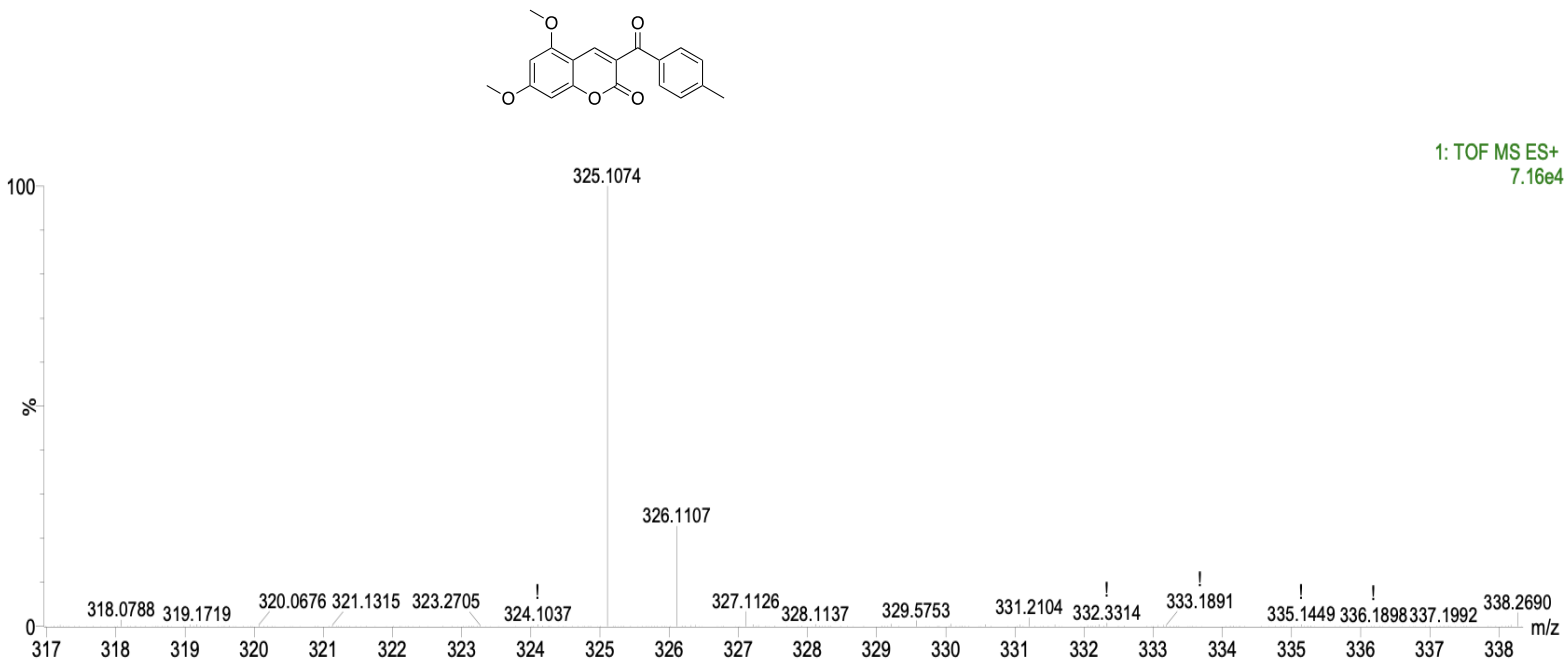

Figure S6. HRMS of 1. 


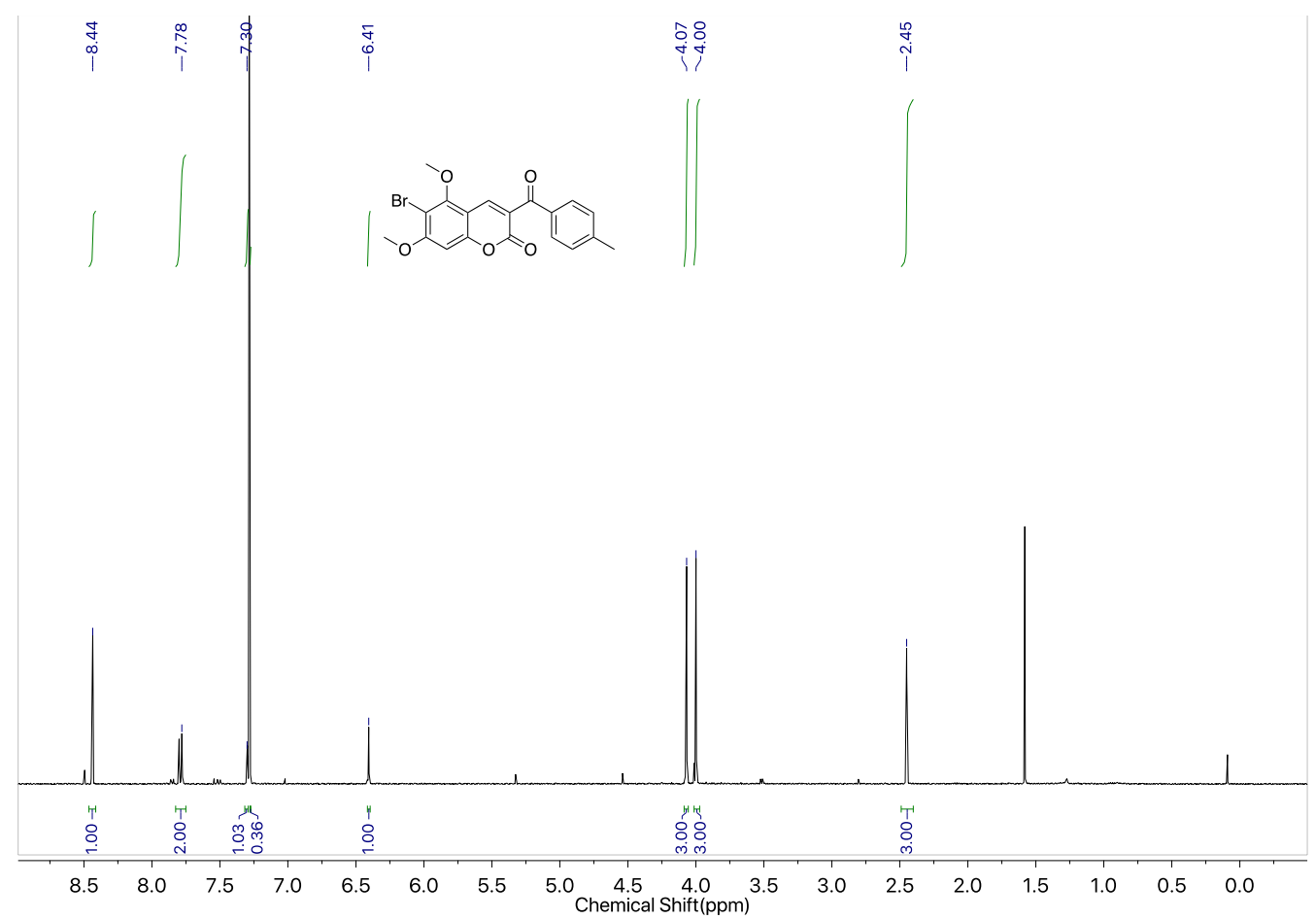

Figure S7. ${ }^{1} \mathrm{H}$ NMR of 2.

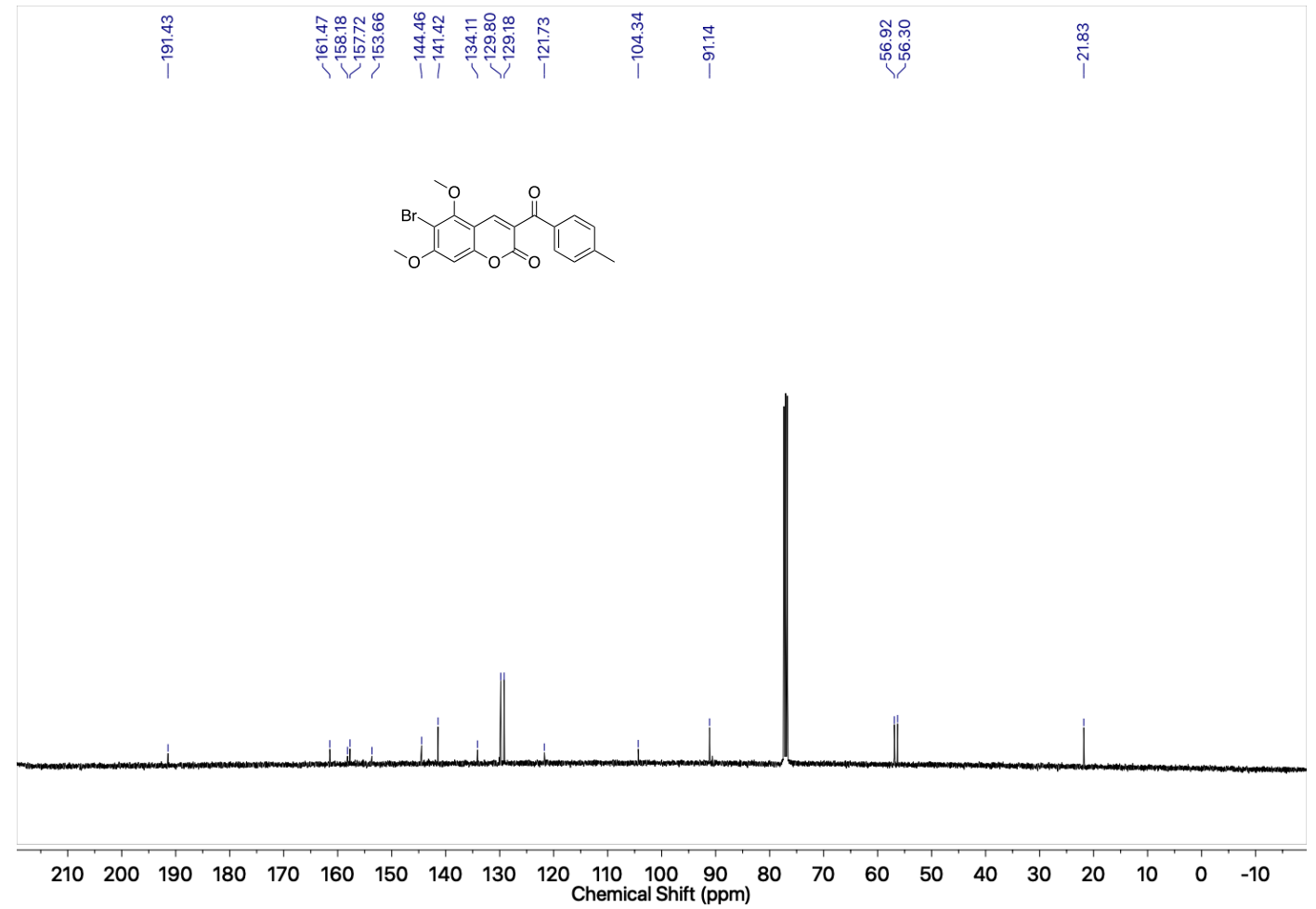

Figure S8. ${ }^{13} \mathrm{C}$ NMR of 2. 


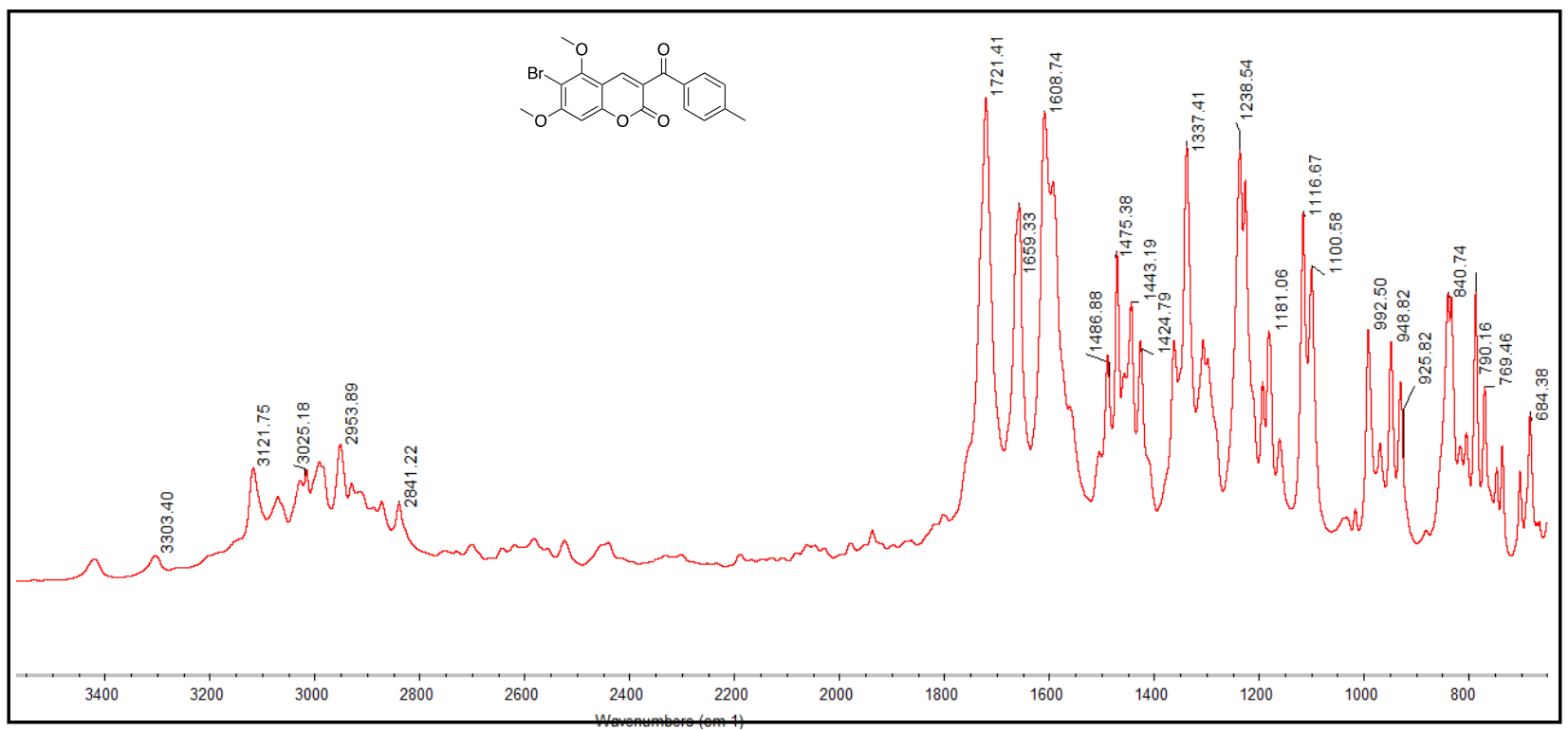

Figure S9. FTIR spectra of 2.

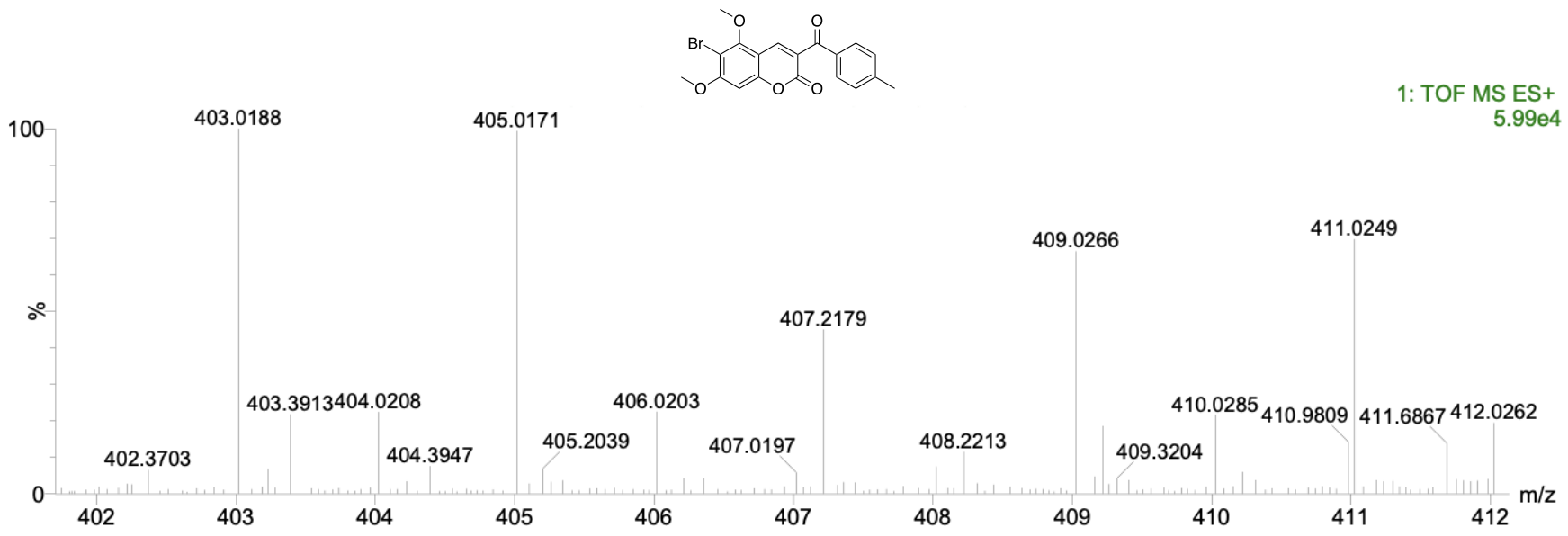

Figure S10. HRMS of 2. 


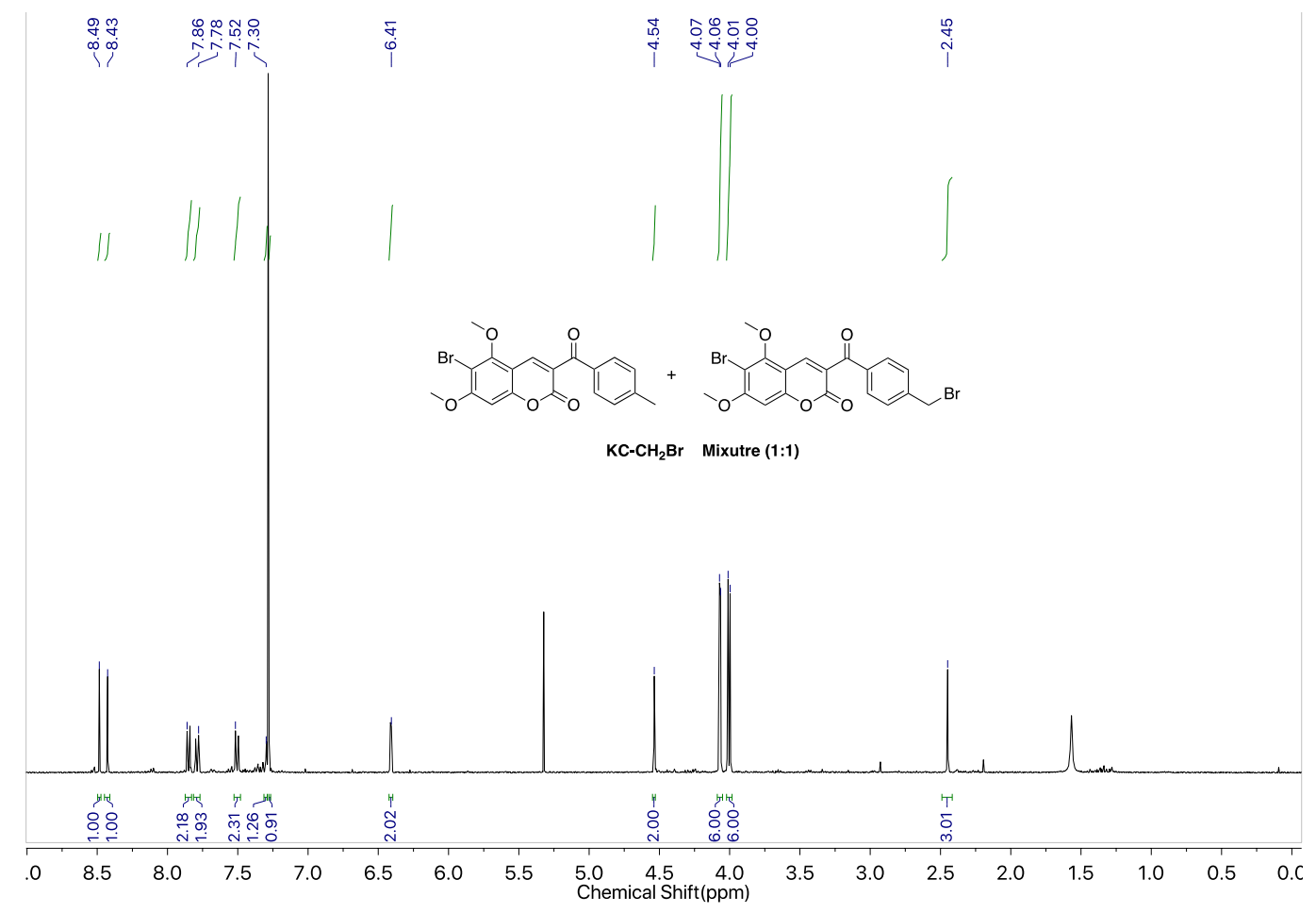

Figure S11. ${ }^{1} \mathrm{H}$ NMR of mixture containing both $\mathbf{2}$ and $\mathbf{3}$.

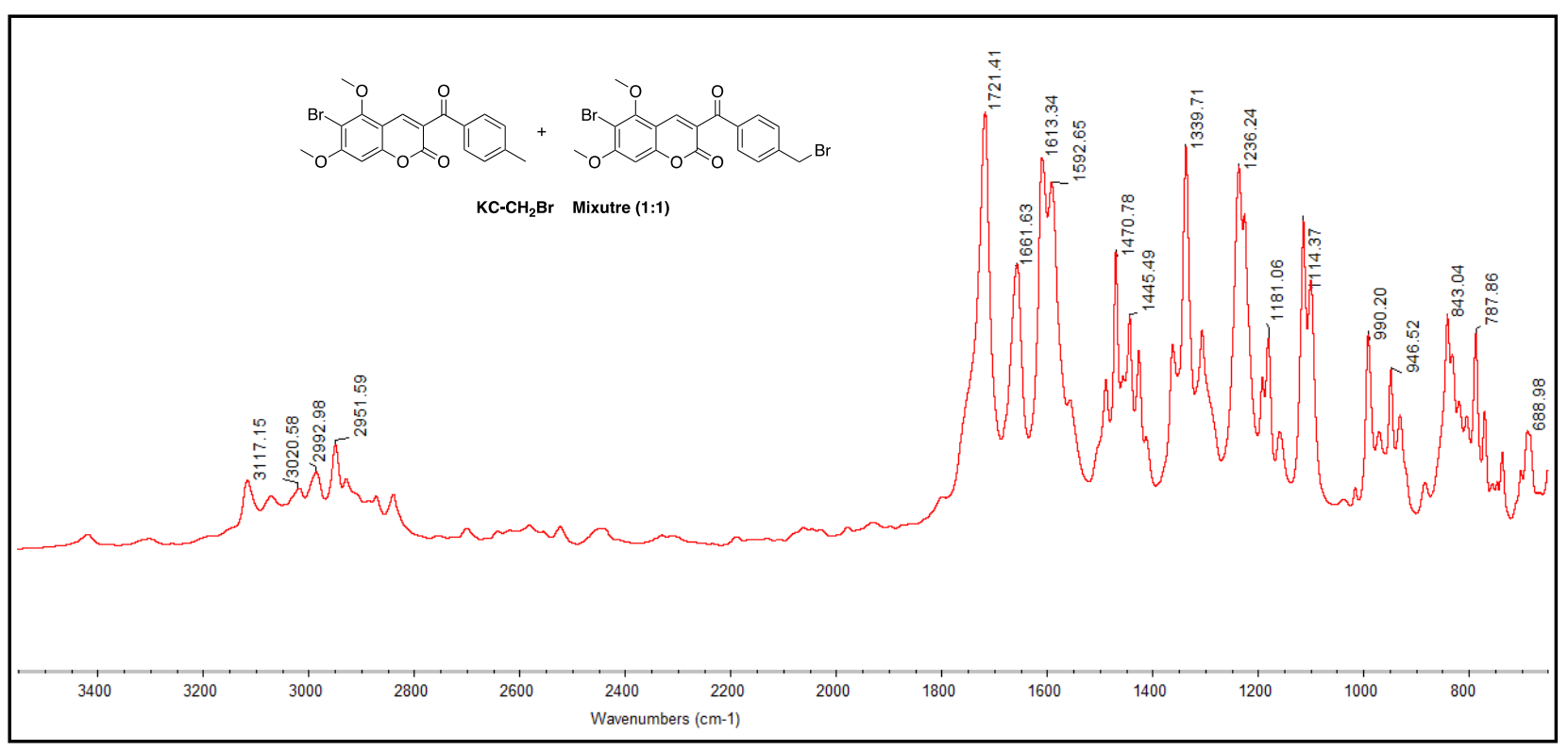

Figure S12. FTIR spectra of mixture containing both $\mathbf{2}$ and $\mathbf{3}$. 

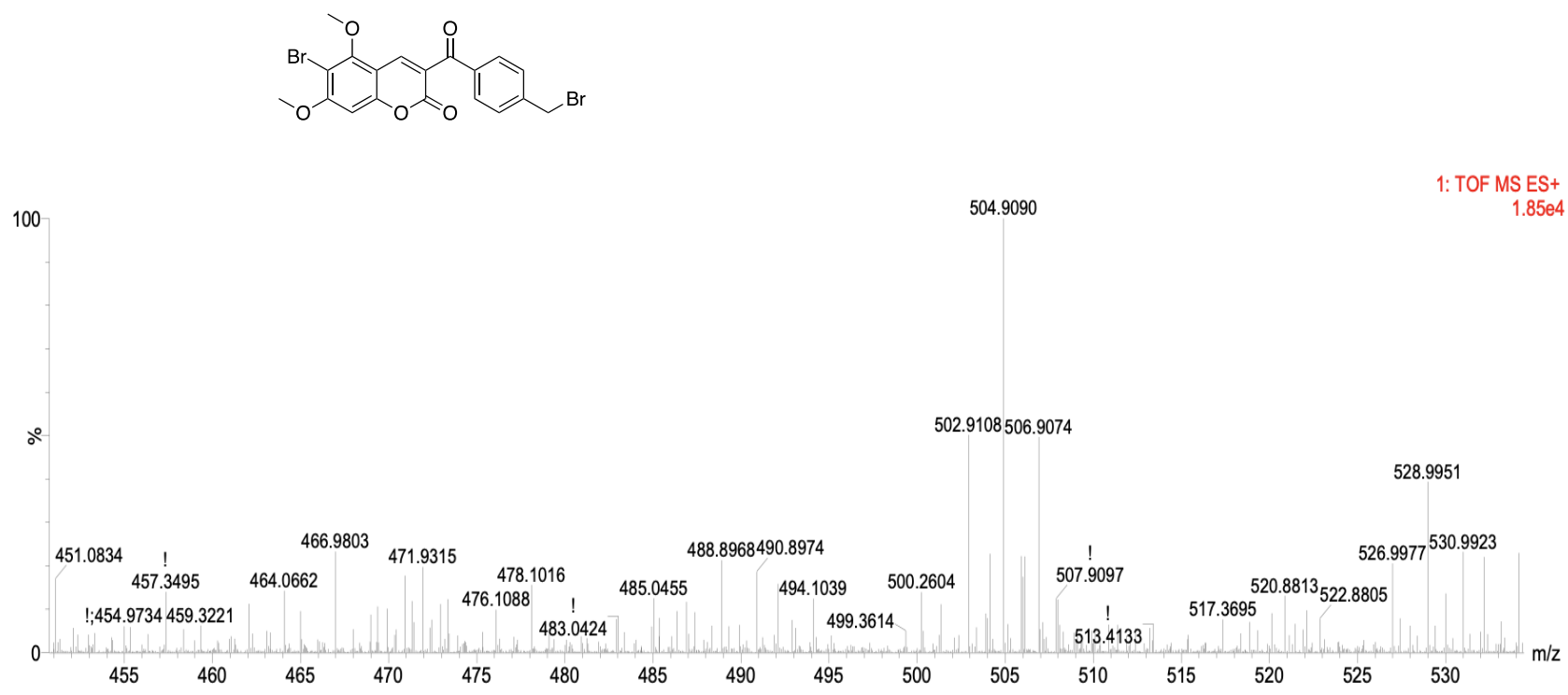

Figure S13. HRMS of the mixture shows the presence of compound 3.

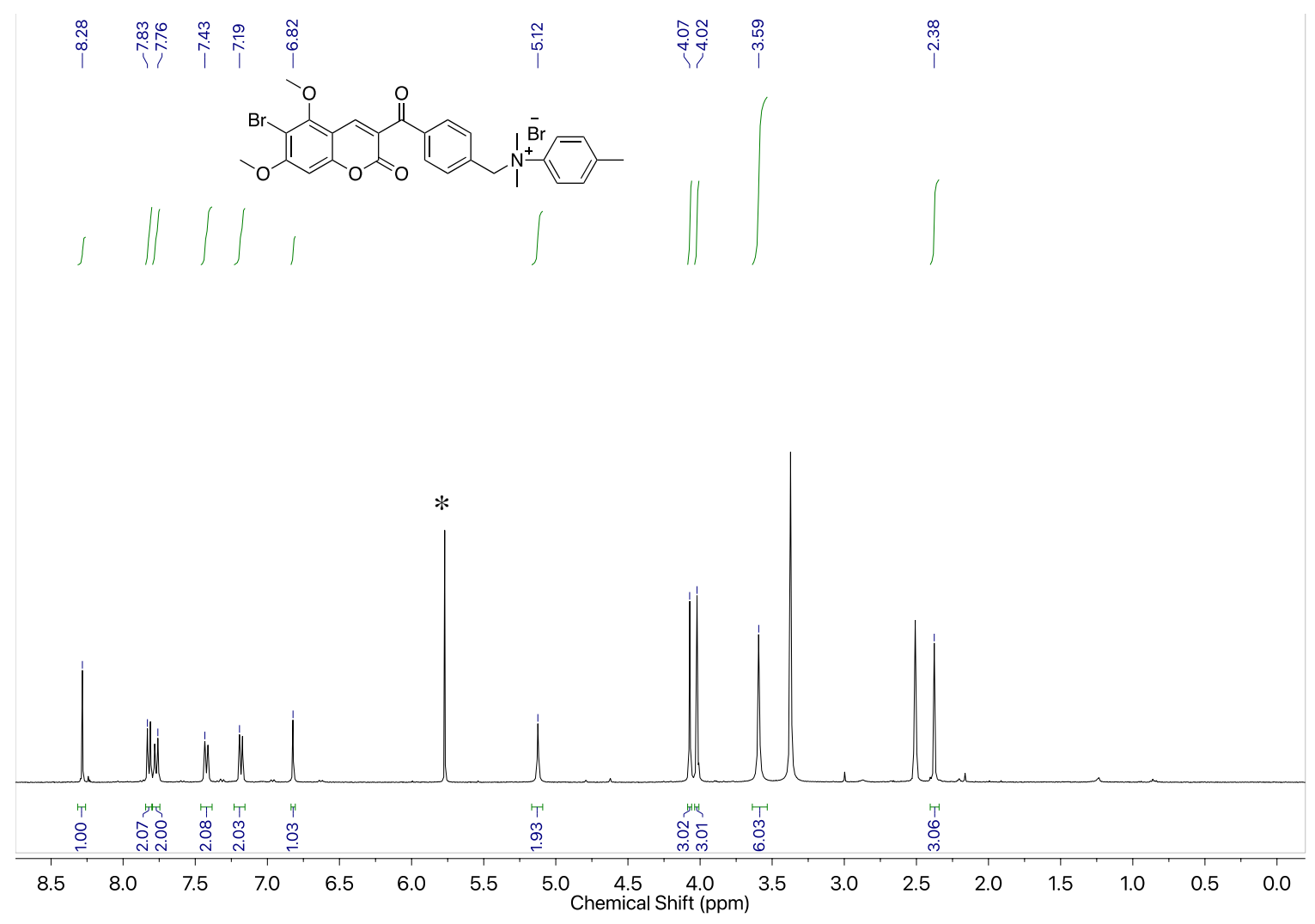

Figure S14. ${ }^{1} \mathrm{H}$ NMR of 4 . (* indicates residual solvent) 


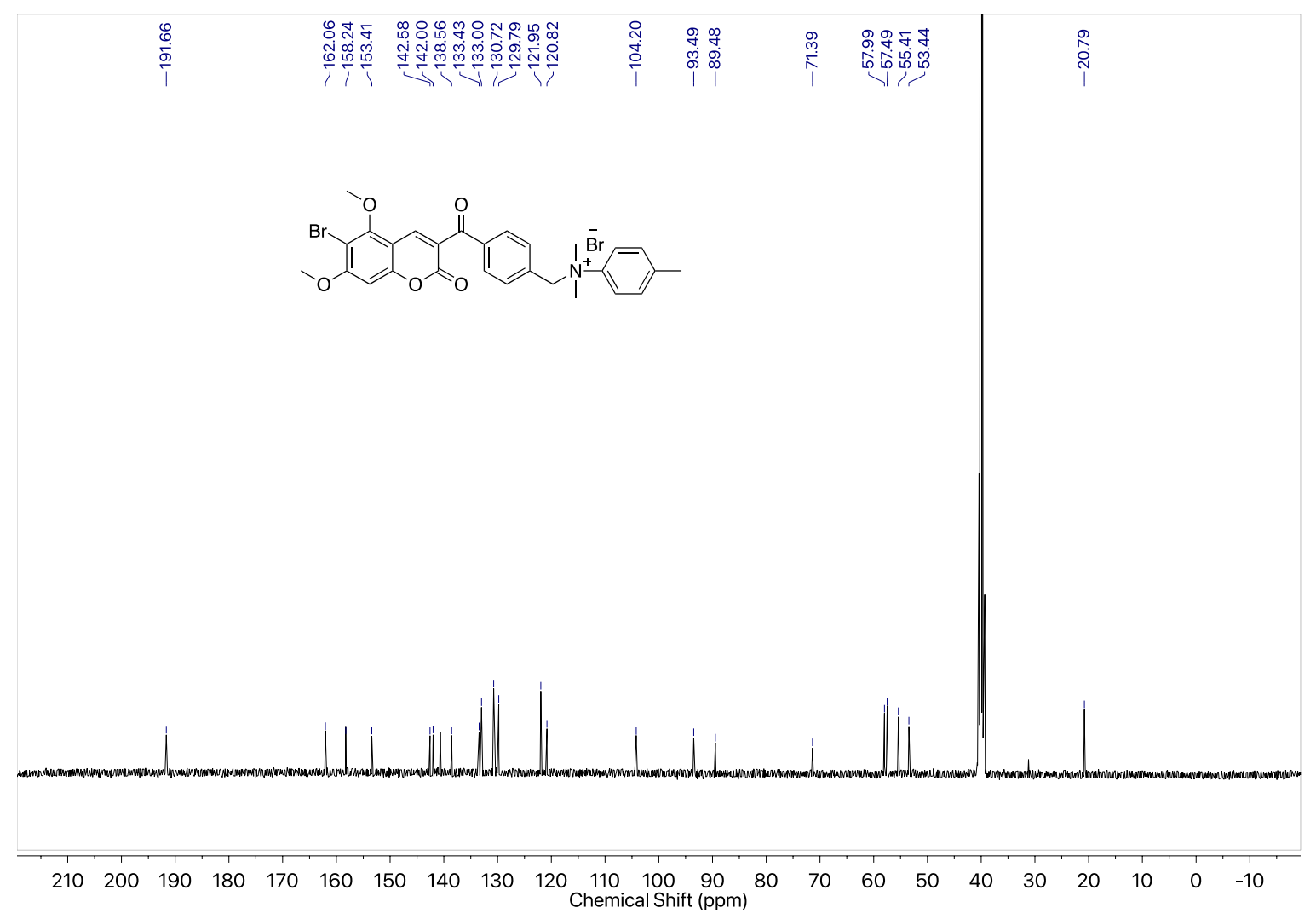

Figure S15. ${ }^{13} \mathrm{C}$ NMR of 4.

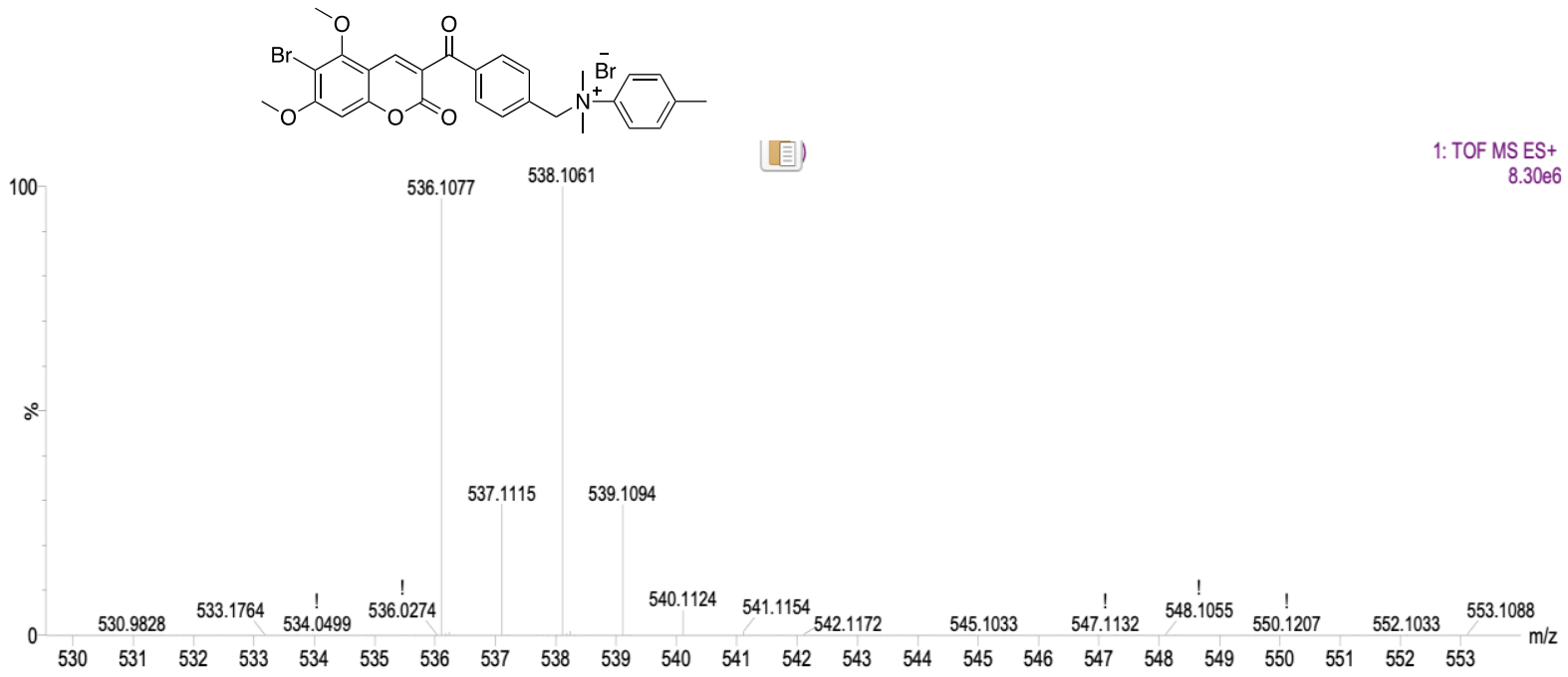

Figure S16. HRMS of 4. 


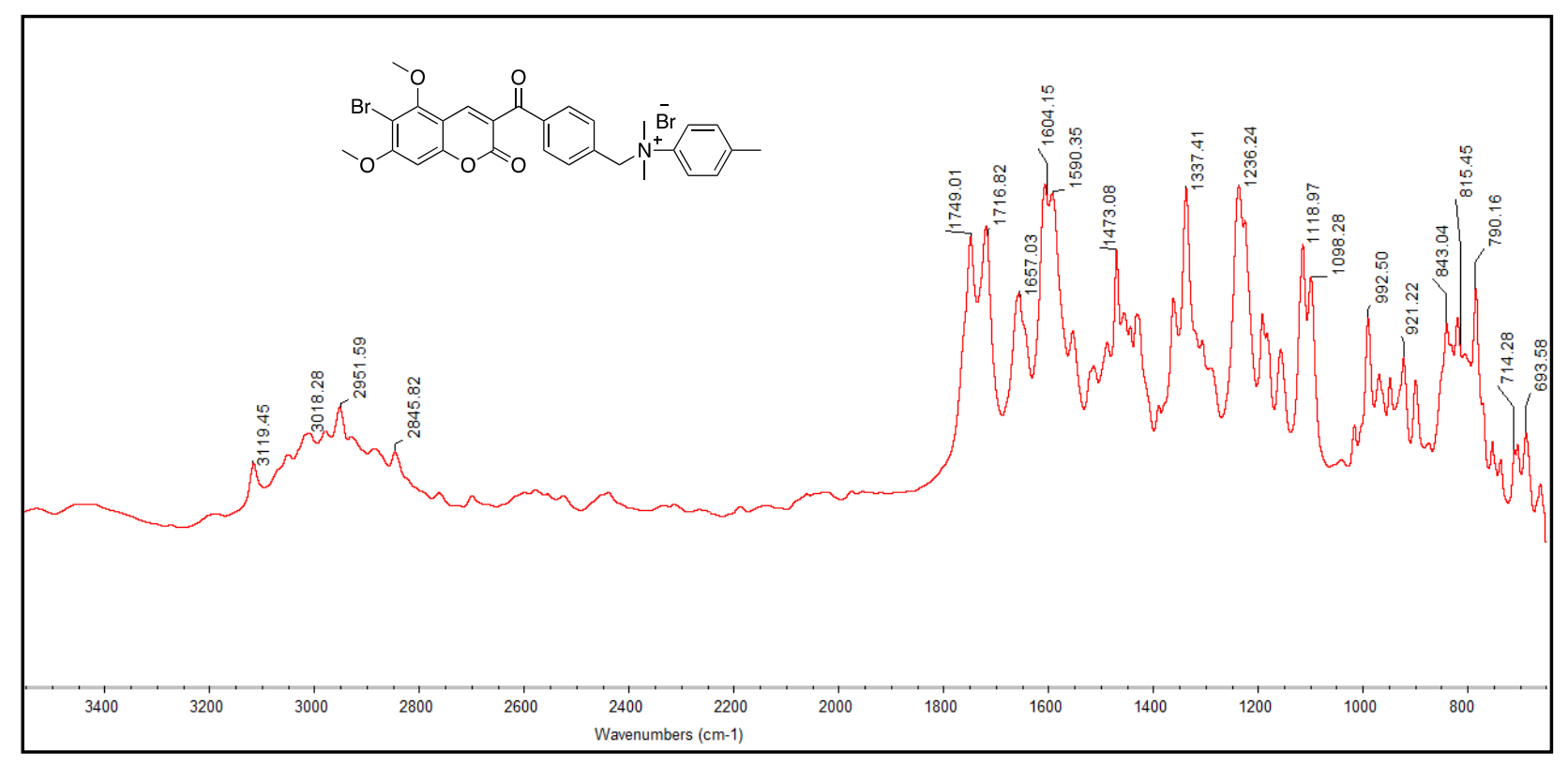

Figure S17. FTIR spectra of 4.

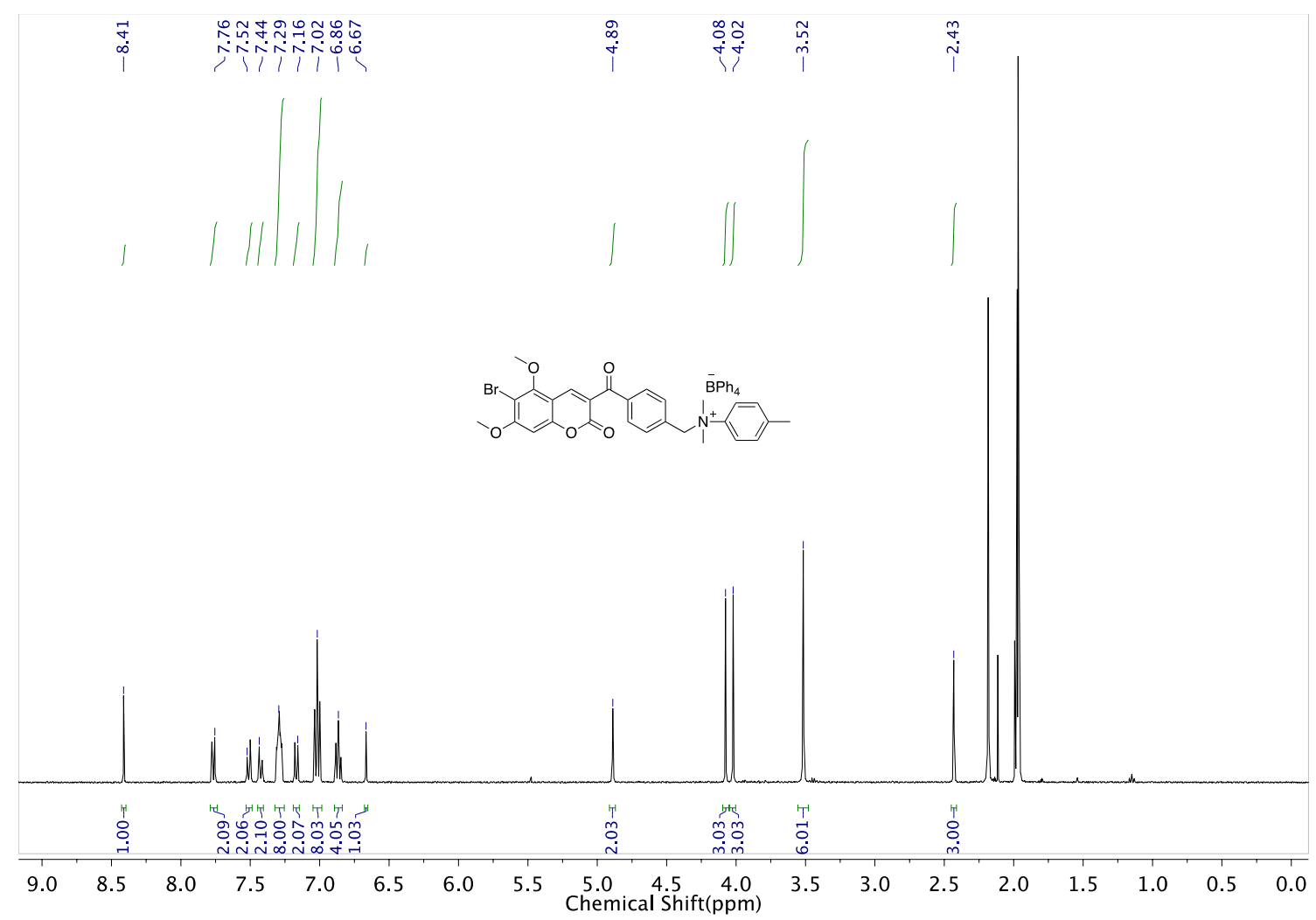

Figure S18. ${ }^{1} \mathrm{H}$ NMR of 5 . 


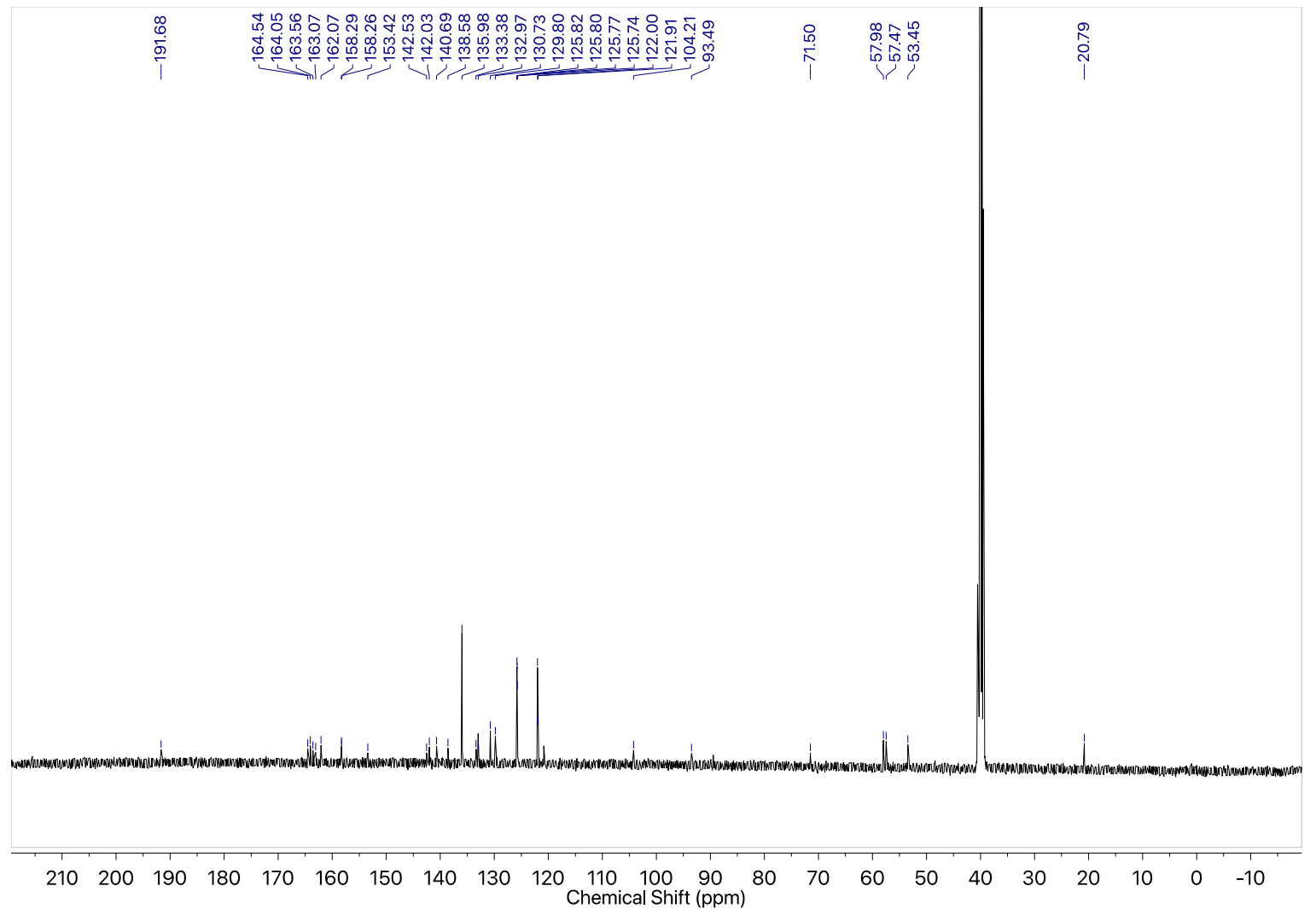

Figure S19. ${ }^{13} \mathrm{C}$ NMR of 5 .

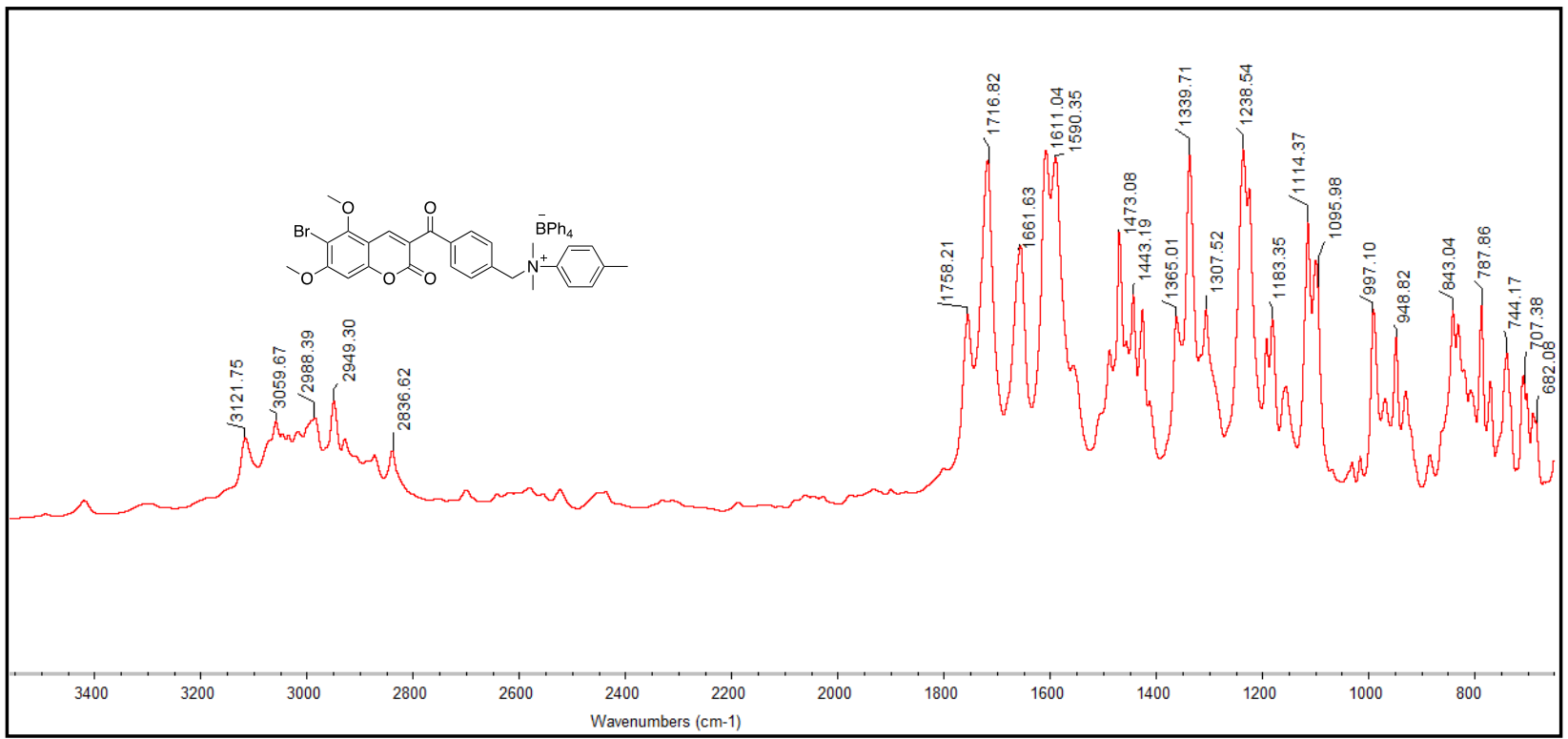

Figure S20. FTIR spectra of 5. 


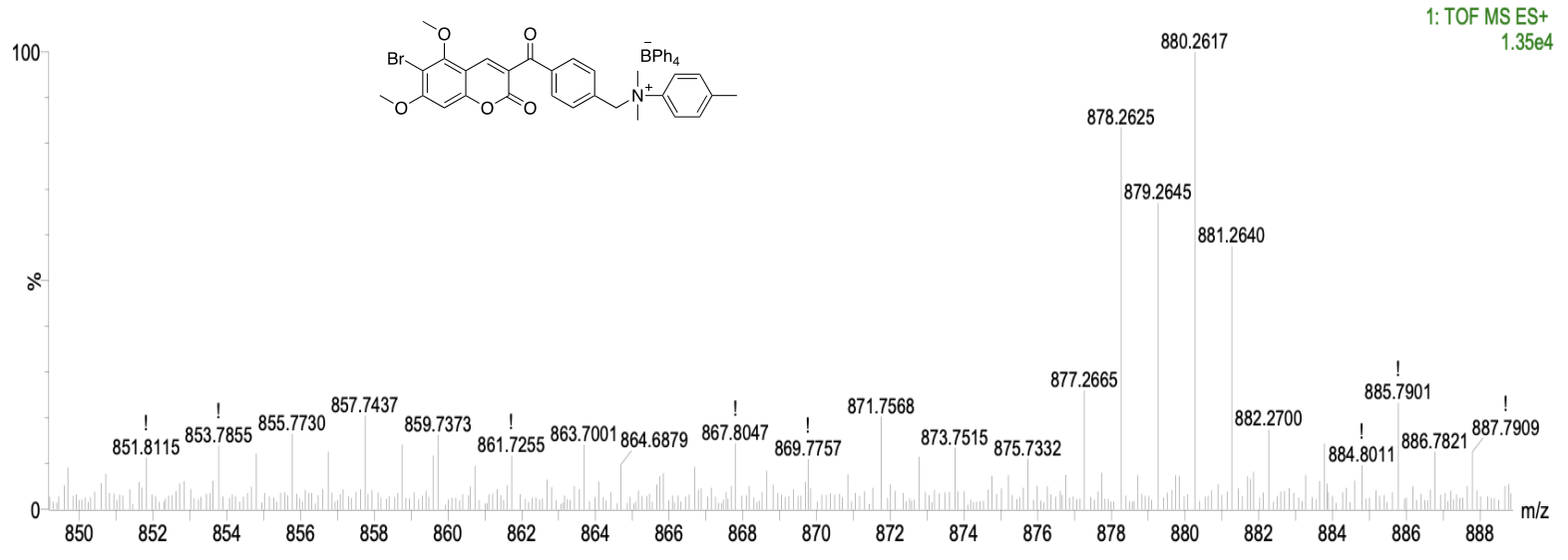

Figure S21. HRMS of 5.

\section{Effect of 6-bromo substitution}
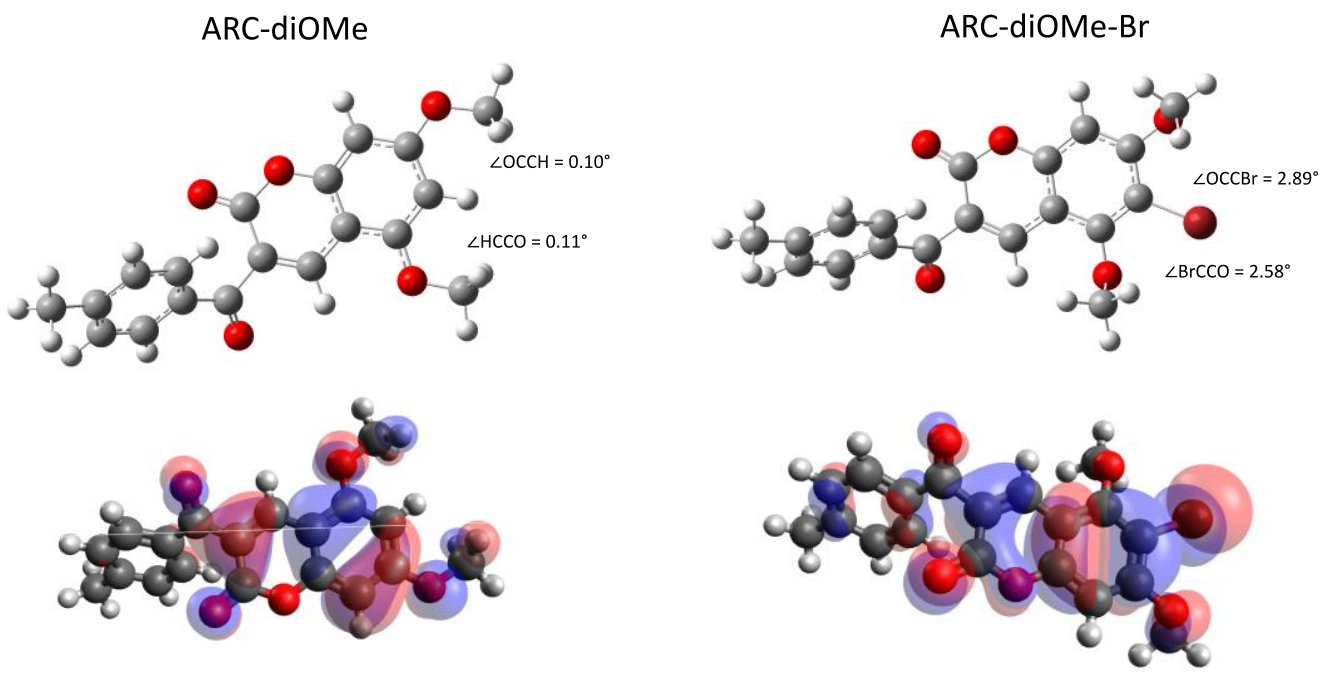

Figure S22. The effect of 6-bromo substitution upon ARC-diOMe. The dihedral angles between the methoxy substituents and the aromatic ring increased, which reduced the electron-donating effect of methoxy substituents. Also, the electron withdrawing bromine has a strong overlap with the pi orbital. 


\section{Ionic Complexation}

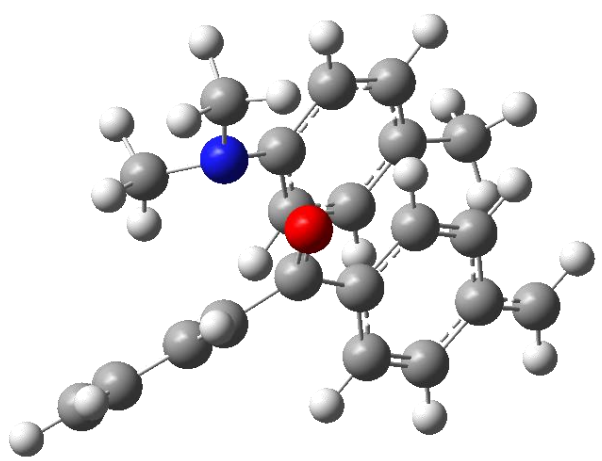

Figure S23. Complexation of BP anion and DMPT ARC via electrostatic attraction.

Table S1. Energetics of $\mathrm{HM}_{2}$ and $\mathrm{ET}_{2}$ in 4 PBGs with ionic complexation (IC) and without ionic complexation (NIC). Without ionic complexation as part of the reaction mechanism, the reaction is not kinetically feasible at room temperature.

\begin{tabular}{|c|c|c|c|c|}
\hline & BP & ARC & ARC-diOMe & ARC-diOMe-Br \\
\hline $\mathrm{HM}_{2}$ (IC) & -16.8 & -7.7 & -11.5 & -6.4 \\
\hline $\mathrm{ET}_{2}$ (IC) & 12.6 & 13.2 & 12.9 & 14.8 \\
\hline $\mathrm{HM}_{2}$ (NIC) & 39.6 & 48.2 & 45.6 & 50.3 \\
\hline $\mathrm{ET}_{2}$ (NIC) & -43.8 & -42.7 & -44.2 & -41.9 \\
\hline
\end{tabular}<smiles>Cc1ccc(C(=O)c2ccccc2)cc1</smiles>

BP<smiles>Cc1ccc(C(=O)c2cc3ccccc3oc2=O)cc1</smiles>

KC<smiles>COc1cc(OC)c2cc(C(=O)c3ccc(C)cc3)c(=O)oc2c1</smiles>

KC-2OMe<smiles>Cc1ccc(C(=O)c2cc3cc(F)cc(F)c3oc2=O)cc1</smiles>

KC-2F<smiles>Cc1ccc(C(=O)c2cc3cc(O)c(O)cc3oc2=O)cc1</smiles>

$\mathrm{KC}-2 \mathrm{OH}$<smiles>CCc1ccc(C(=O)c2cc3cc(C(C)(C)C)cc(C(C)(C)C)c3oc2=O)cc1</smiles>

KC-2Tbt<smiles>Cc1ccc(C(=O)c2cc3cc(Cl)cc(Cl)c3oc2=O)cc1</smiles>

KC-2Cl

\begin{tabular}{|c|c|c|c|c|c|c|c|}
\hline & BP & & KC-2OMe & KC-2F & $\mathrm{KC}-2 \mathrm{OH}$ & KC-2Tbt & $\mathrm{KC}-2 \mathrm{Cl}$ \\
\hline lambdaMax1 (nm) & 328.94 & 330.63 & 338.15 & ; $\quad 331.33$ & 333.16 & 330.59 & $\quad 331.37$ \\
\hline Absorptivity1 (f) & 0.002 & 0.02 & 0.46 & 0.01 & 0.19 & 0.03 & 0.01 \\
\hline eta1 ( $\mathrm{L} \mathrm{mol}-1 \mathrm{~cm}-1)$ & 68.83076945 & 732.8453 & 18422.35 & 498.0109 & 7692.851 & 1012.217 & 534.4507 \\
\hline lambdaMax2 (nm) & 249.73 & 294.68 & 321.63 & 296.00 & 320.48 & 304.87 & 299.03 \\
\hline Absorptivity2 (f) & 0.47 & 0.53 & 0.33 & 0.32 & 0.34 & 0.30 & 0.29 \\
\hline eta2 ( $\mathrm{L} \mathrm{mol}-1 \mathrm{~cm}-1)$ & 19029.68332 & 21361.83 & 13361.27 & 13085.94 & 13636.59 & 12102.07 & 11721.48 \\
\hline
\end{tabular}

Figure S24. Various ARC derivatives that are generated from available precursors 


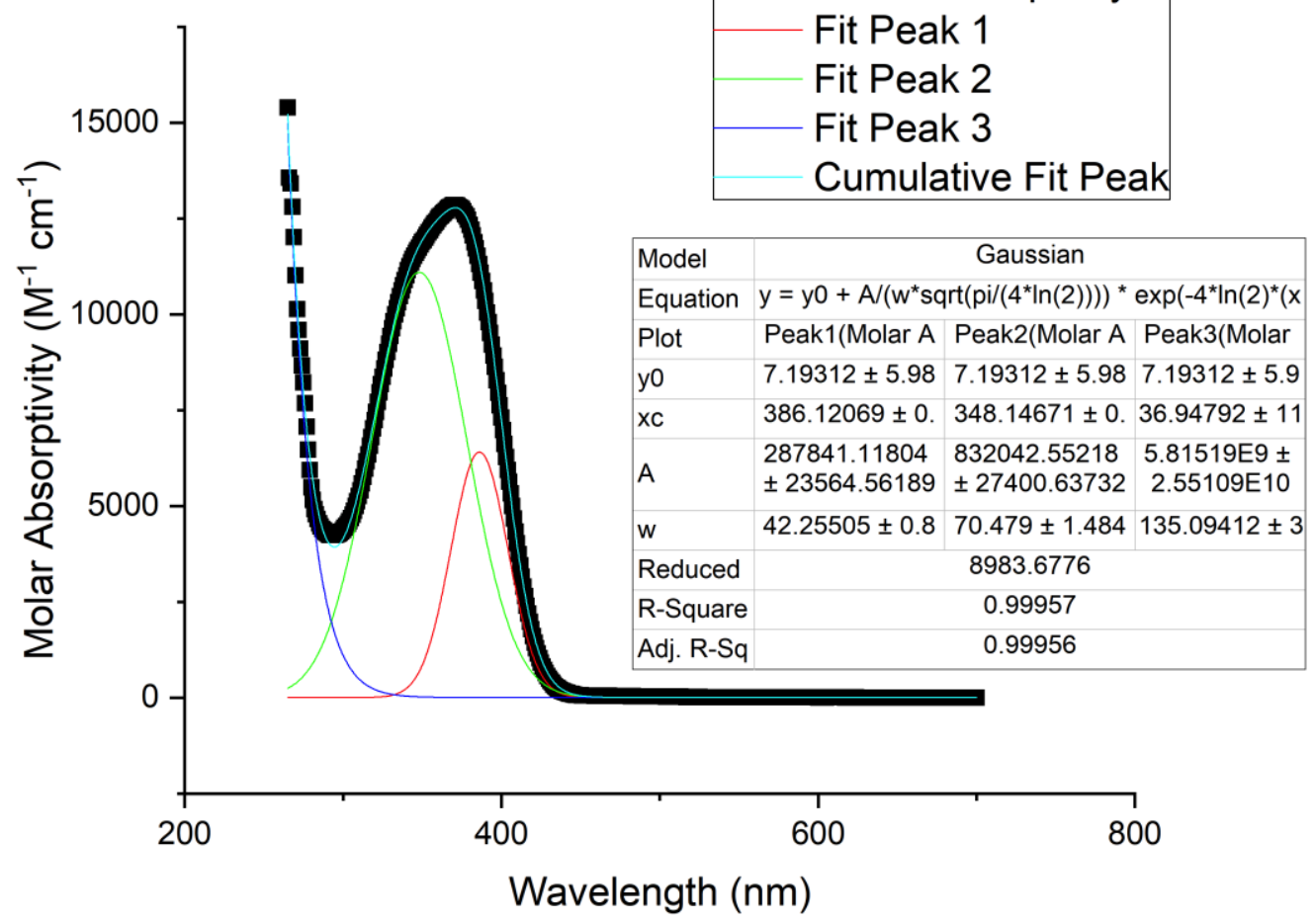

Figure S25. Deconvolution of first and second absorptions as the computationally predicted $\mathrm{n} \rightarrow \pi^{*}$ and $\pi \rightarrow \pi^{*}$ transitions

\section{Depth of cure}

According to the Beer-Lambert equation, $A=\varepsilon c l$ where $\varepsilon$ is molar absorptivity, $c$ is molar concentration of photochemical species, and $l$ is path length. The UV-Vis spectra (Figure 8) indicate that visible DCPI absorbs light at $365 \mathrm{~nm}$ with $\varepsilon=12924 \mathrm{M}^{-1} \mathrm{~cm}^{-1}$, at $405 \mathrm{~nm}$ with 5710 $\mathrm{M}^{-1} \mathrm{~cm}^{-1}$, at $420 \mathrm{~nm}$ with $1620 \mathrm{M}^{-1} \mathrm{~cm}^{-1}$, at $455 \mathrm{~nm}$ with $50 \mathrm{M}^{-1} \mathrm{~cm}^{-1}$, and at $470 \mathrm{~nm}$ with $25 \mathrm{M}^{-1}$ $\mathrm{cm}^{-1}$. The molar concentration $[c]$ in our experiments was $0.00766 \mathrm{~mol} / \mathrm{L}$.

The optically thin film approximation requires $>90 \%$ of transmission $(\mathrm{T}){ }^{6}$ The Beer-Lambert Law can be reorganized into $A=-\log T$. Therefore, A is 0.0458 . 
The path lengths $(l)$ were calculated to be 4.6, 10.5, 36.9, 1194.7, and 2389.4 micrometers for the respective wavelengths of $365,405,420,455$, and $470 \mathrm{~nm}$. At $365 \mathrm{~nm}$, the good depth of cure would be near impossible to achieve due to a high molar absorptivity resulting in very strong light attenuation at the surface level. However, the longer wavelength (455 and $470 \mathrm{~nm}$ ) is able to penetrate milliliters into the samples with $90 \%$ intensity retention, allowing for deep curing.

Table S2. Path length (1) allowing $90 \%$ transmission of the initial intensity dependent on wavelength at $0.00766 \mathrm{~mol} / \mathrm{L}$ of concentration (c) used in our kinetic study.

\begin{tabular}{|c|c|c|c|}
\hline Wavelength $(\mathrm{nm})$ & $\mathrm{c}\left(\mathrm{M}^{-1} \mathrm{~cm}^{-1}\right)$ & $\mathrm{I}(\mathrm{cm})$ & $\mathrm{I}$ (micrometer) \\
\hline 365 & 12924 & 0.00046 & 4.6 \\
\hline 405 & 5710 & 0.00105 & 10.5 \\
\hline 420 & 1620 & 0.00369 & 36.9 \\
\hline 455 & 50 & 0.11947 & 1194.7 \\
\hline 470 & 25 & 0.23894 & 2389.4 \\
\hline
\end{tabular}

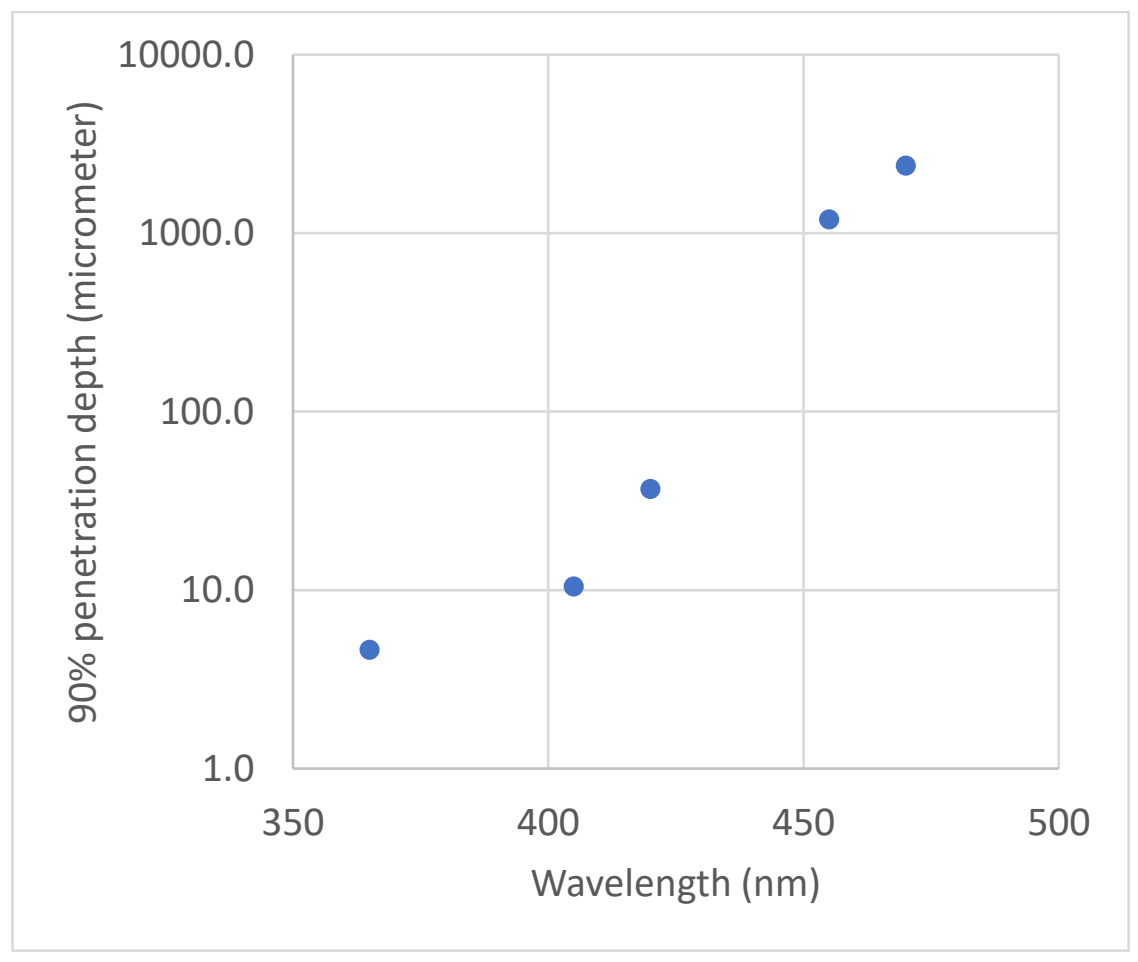

Figure S26. Logarithmic relationship between wavelength and 90\% penetration depth based on the Beer-Lambert law. 


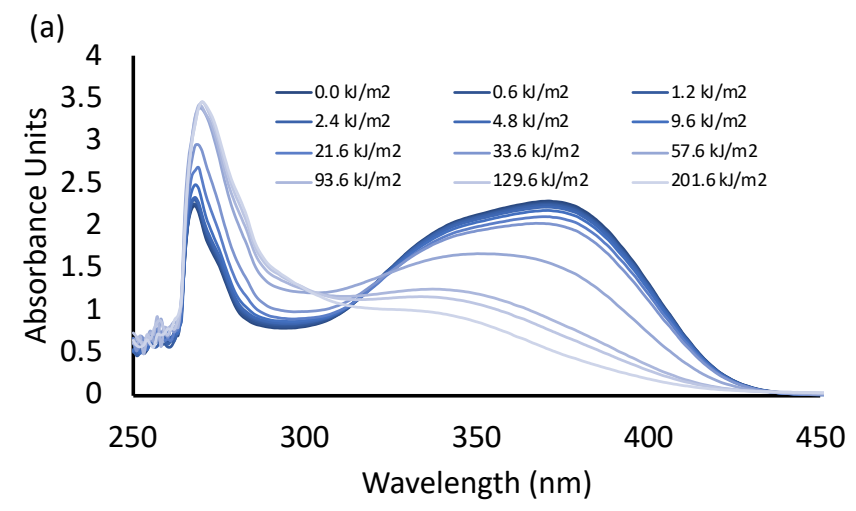

(b)

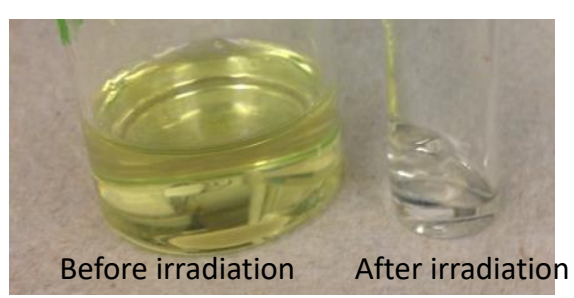

Figure S27. (a) Photobleaching experiment of increasing doses. $1 \mathrm{~mW} / \mathrm{cm}^{2}$ is used from $0.6 \mathrm{~kJ} / \mathrm{m}^{2}$ to $9.6 \mathrm{~kJ} / \mathrm{m}^{2}, 10$ $\mathrm{mW} / \mathrm{cm}^{2}$ is used from $21.6 \mathrm{~kJ} / \mathrm{m}^{2}$ to $57.6 \mathrm{~kJ} / \mathrm{m}^{2}, 30 \mathrm{~mW} / \mathrm{cm}^{2}$ is used from 93.6 to $201.6 \mathrm{~kJ} / \mathrm{m}^{2}$. The concentration was $0.16 \mathrm{mM}$ in DMF. (b) color change upon irradiation from light yellow to clear due to photobleaching.

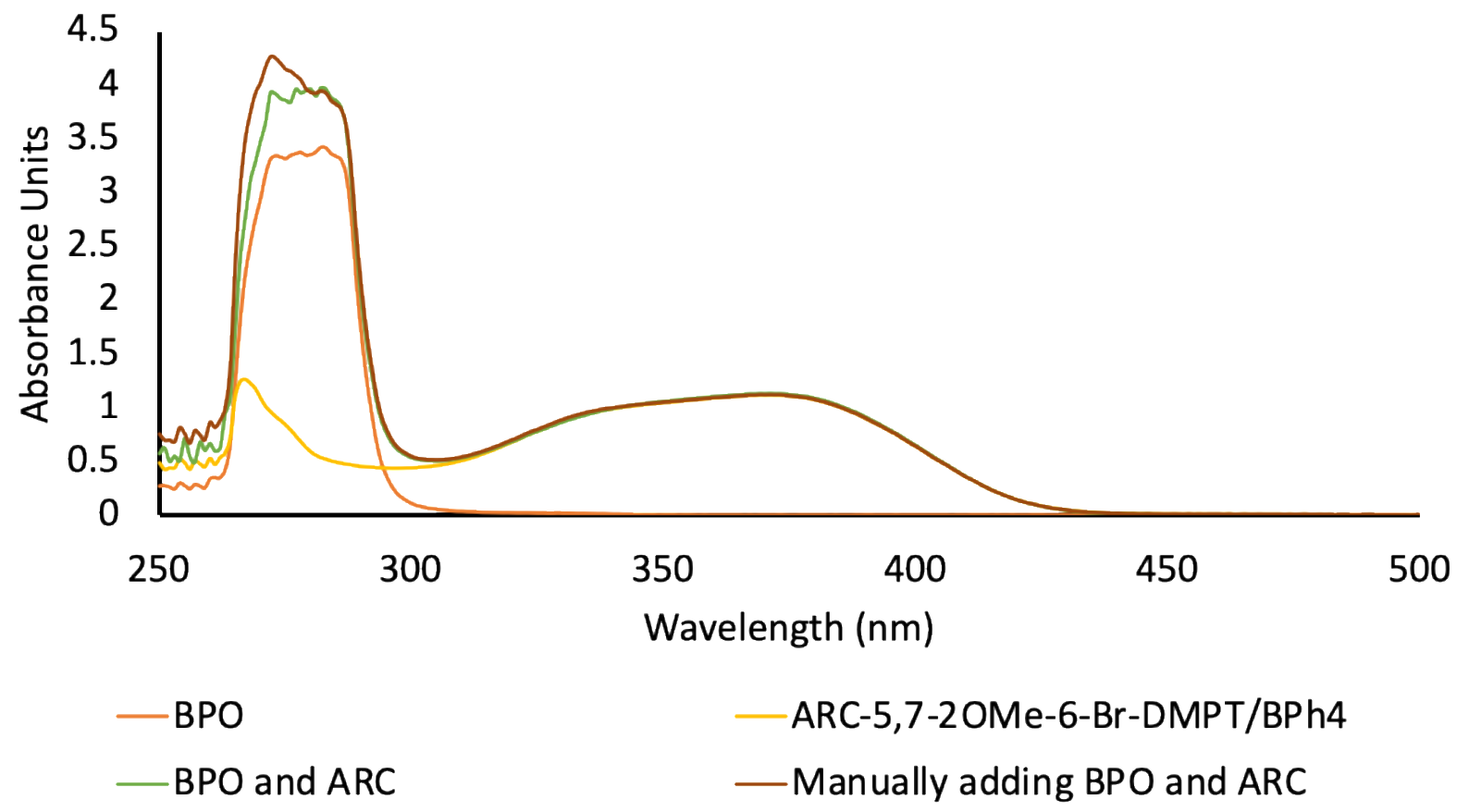

Figure S28. UV-Vis Spectra of DCPI components. BPO and PBG do not react with each other without irradiation. 


\section{Kinetic property calculations}

Based on a steady-state analysis, the rate of methacrylate free radical polymerization $\left(\mathrm{R}_{\mathrm{P}}\right)$ can be expressed as: ${ }^{7}$

$\frac{k_{p}}{k_{t}^{1 / 2}}=\frac{R_{p}}{[M]\left(\varepsilon I_{0} \Phi[I] 1000\right)^{1 / 2}} \quad$ Eq. 1

Where $k_{p}$ is the propagation kinetic constant, and $k_{t}$ is termination kinetic constant. The molar concentration of monomer is represented by $[\mathrm{M}]$, the initiator molar absorption by $\varepsilon$, light intensity by $I_{0}$, initiator efficiency by $\Phi$, and the initiator concentration by $[\mathrm{I}]$. Therefore, the initiator efficiency can be calculated by reorganizing Eq. 1 to:

$\Phi=\frac{k_{t} R_{p}^{2}}{1000 \varepsilon I_{0}[I]\left([M] k_{p}\right)^{2}}$

Eq 2

Based on Figure 10, $R_{p}$ for each system was calculated based on the time that it took the reaction proceed from $5 \%$ to $10 \%$ conversion. $k_{p} / k_{t}^{1 / 2}$ for TEGDMA was obtained from the previous literature, ${ }^{6,7}$ where $\boldsymbol{k}_{\boldsymbol{p}}$ is $516 \mathrm{M}^{-1} \mathrm{~s}^{-1}$ and $k_{t}$ is $5 \times 10^{5} \mathrm{M}^{-1} \mathrm{~s}^{-1}{ }^{7}$ From Figure 8 , the molar absorption for the ARC-PBG at $455 \mathrm{~nm}$ is $\varepsilon=11500 \mathrm{~L} / \mathrm{m} / \mathrm{mol}$, initiator concentration [I] is $0.00766 \mathrm{~mol} / \mathrm{L}$ and light intensity $I_{0}$ is $500 \mathrm{~W} / \mathrm{m}^{2}=1.9 \times 10^{-6} \mathrm{M} * \mathrm{~m} / \mathrm{s}$

Hence, $\boldsymbol{\Phi}$ for DCPI can be determined as:

$$
\Phi=\frac{k_{t} R_{p}^{2}}{1000 \varepsilon I_{0}[I]\left([M] k_{p}\right)^{2}}=\frac{5 * 10^{5} * 0.50^{2}}{1000 * 11500 * 1.9 * 10^{-6} * 0.00766 *(1 * 516)^{2}}=2.82
$$

A similar calculation was performed for PBG. 
Table S3. Rate of polymerization and initiator efficiency of photoinitiators

\begin{tabular}{lll}
\hline & PBG & DCPI \\
$R_{p}\left(\mathrm{~s}^{-1}\right)$ & 0.24 & 0.50 \\
& & \\
$\Phi$ & 0.65 & 2.82 \\
\hline
\end{tabular}

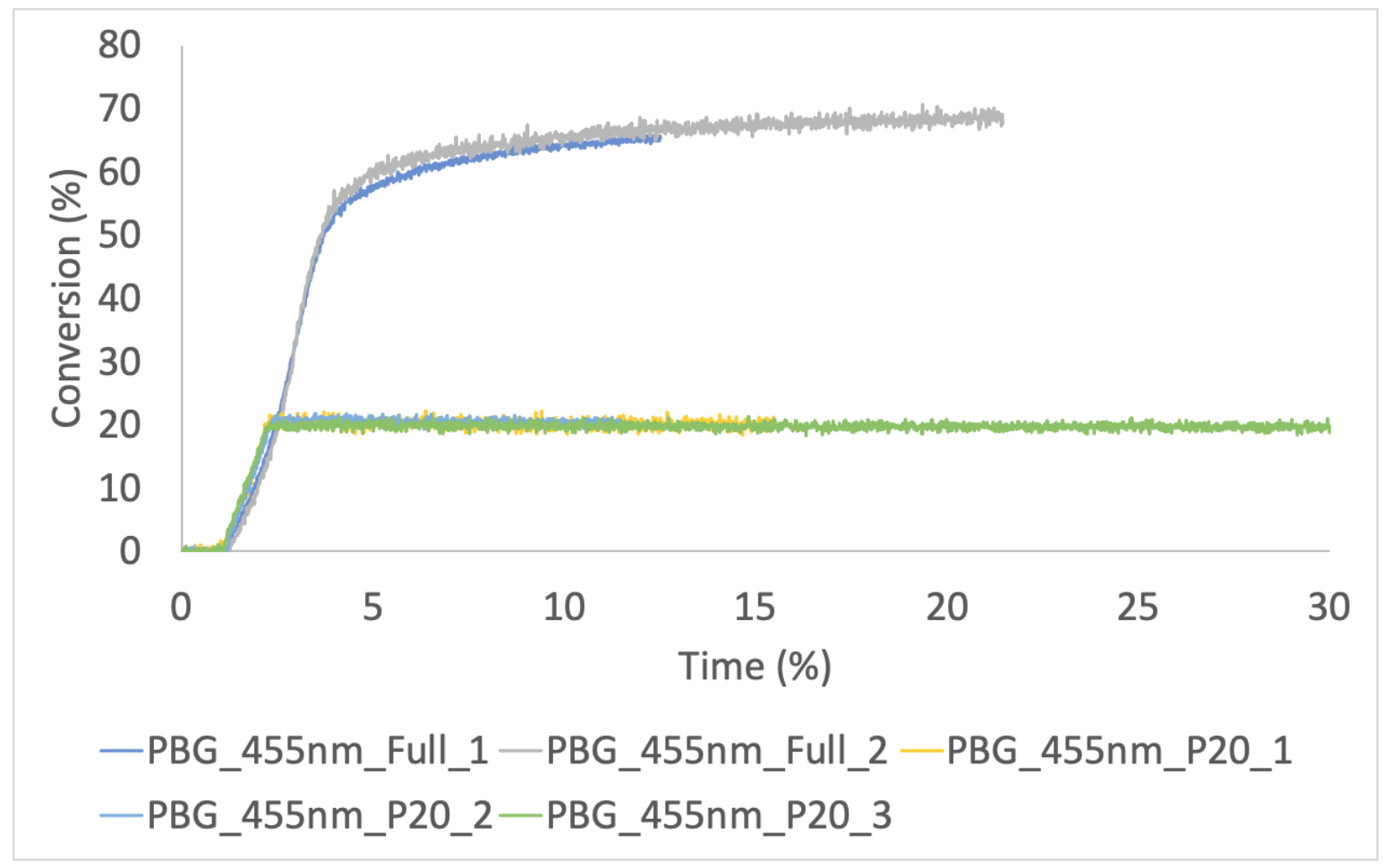

Figure S29. Polymerization profiles of ARC-5,7-diOMe-6- $\mathrm{Br}$ under full and 20\% partial cures. The experimental conditions include the initiator of $0.6 \mathrm{wt} \%$ ARC-PBG; the resin of $80 \mathrm{wt} \%$ TEGDMA and $20 \mathrm{wt} \% \mathrm{MBL}$; and 50 $\mathrm{mW} / \mathrm{cm}^{2} 455 \mathrm{~nm}$ LED. 


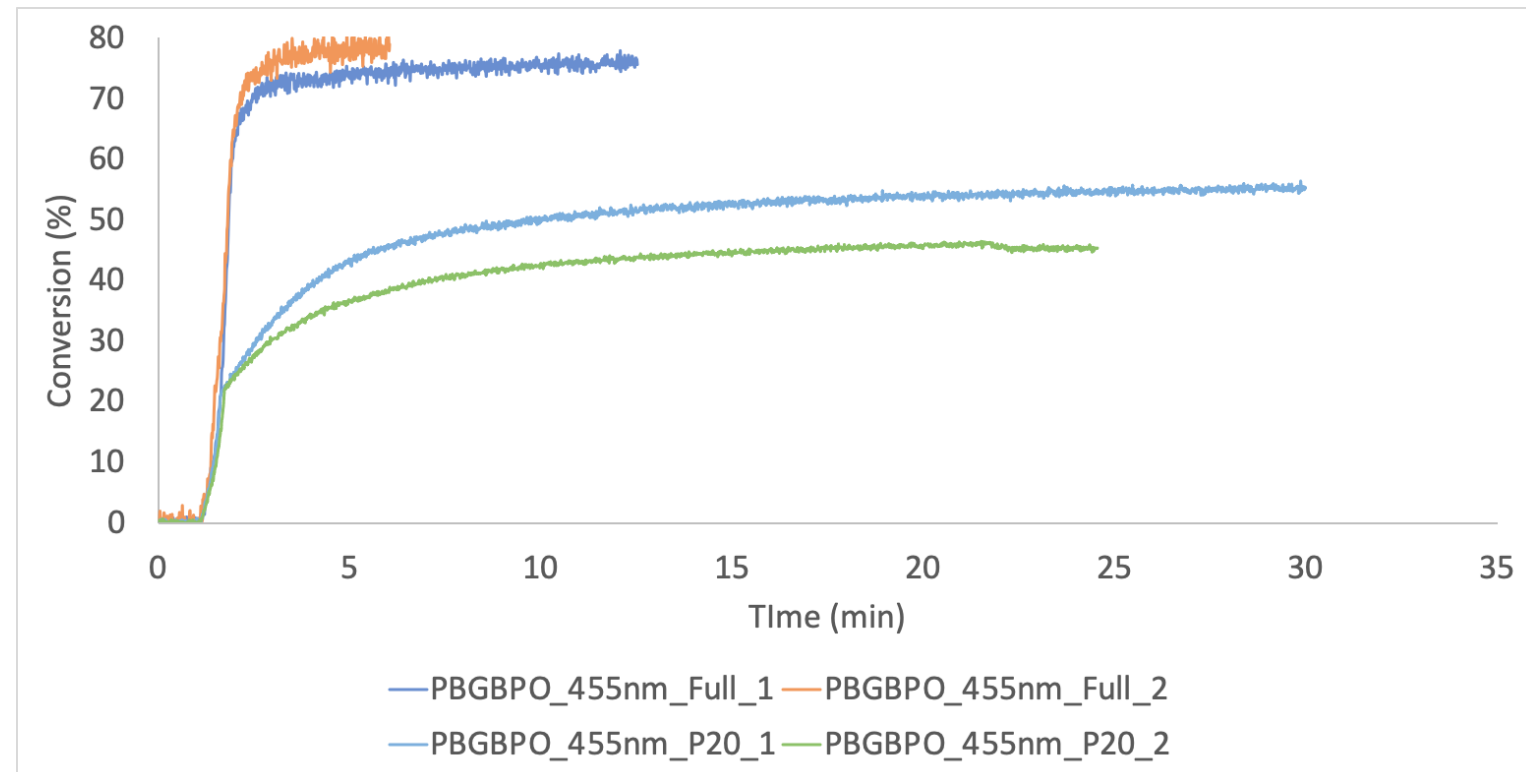

Figure S30. Polymerization profiles of ARC-5,7-diOMe-6-Br with BPO under full and 20\% partial cure. The experimental conditions include the initiator of $0.6 \mathrm{wt} \%$ ARC-PBG and $1.8 \mathrm{wt} \%$ BPO; the resin of $80 \mathrm{wt} \%$ TEGDMA and $20 \mathrm{wt} \% \mathrm{MBL}$; and $50 \mathrm{~mW} / \mathrm{cm}^{2} 455 \mathrm{~nm}$ LED.

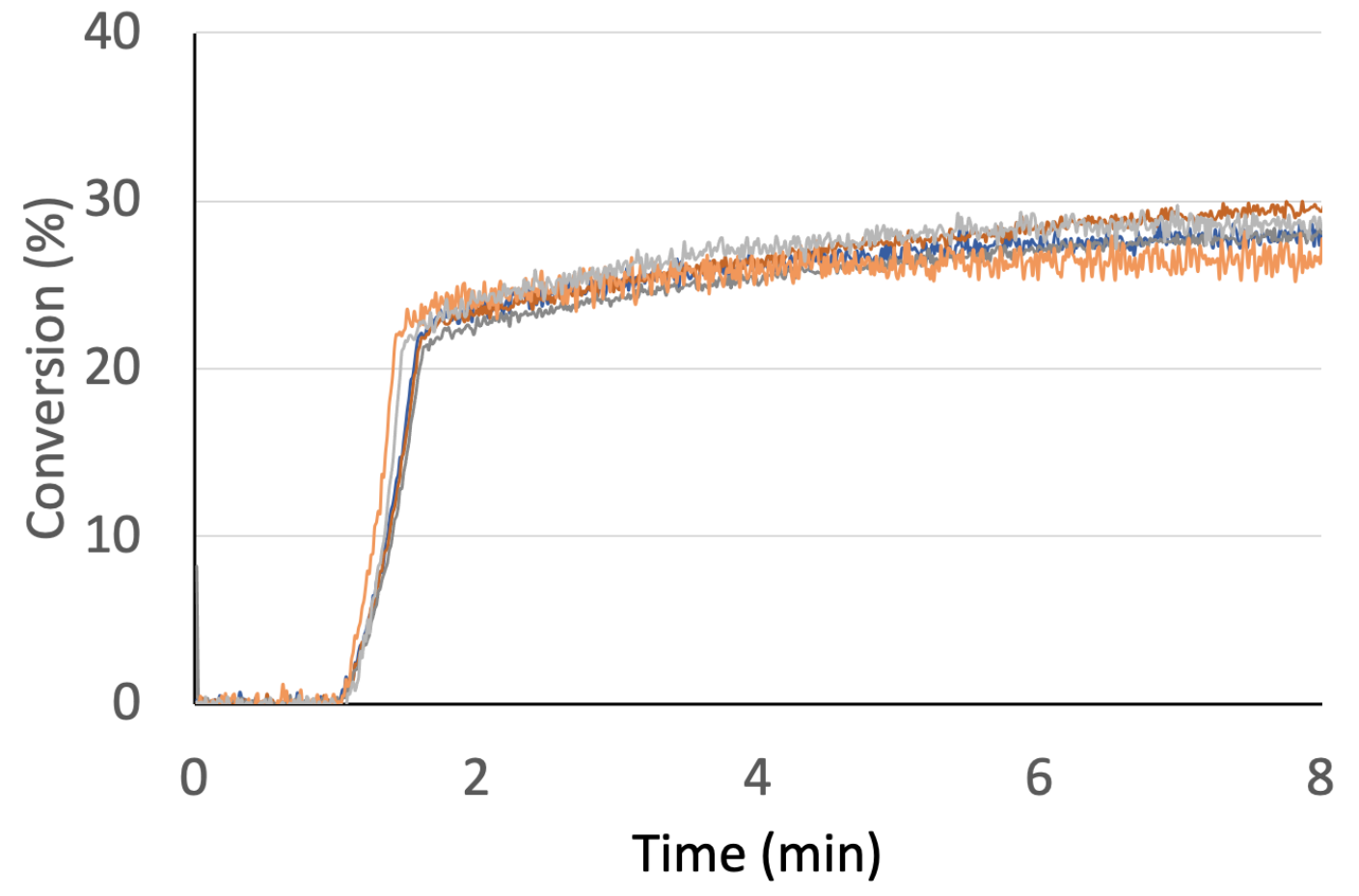

$$
\begin{aligned}
& \text {-PBGBPO_365nm_P20_1-PBGBPO_365nm_P20_2-PBGBPO_365nm_P20_3 } \\
& \text { —PBGBPO_405nm_P20_1-PBGBPO_405nm_P20_2 }
\end{aligned}
$$

Figure S31. Polymerization profiles of ARC-5,7-diOMe-6-Br with BPO under full and 20\% partial cures with a 365 $\mathrm{nm}$ LED and a $405 \mathrm{~nm}$ LED. The experimental conditions include the initiator of $0.6 \mathrm{wt} \%$ ARC-PBG and $1.8 \mathrm{wt} \%$ $\mathrm{BPO}$; the resin of $80 \mathrm{wt} \%$ TEGDMA and $20 \mathrm{wt} \% \mathrm{MBL}$; and $10.0 \mathrm{~mW} / \mathrm{cm}^{2} 365 \mathrm{~nm}$ LED and $11.5 \mathrm{~mW} / \mathrm{cm}^{2} 405 \mathrm{~nm}$ LED. 


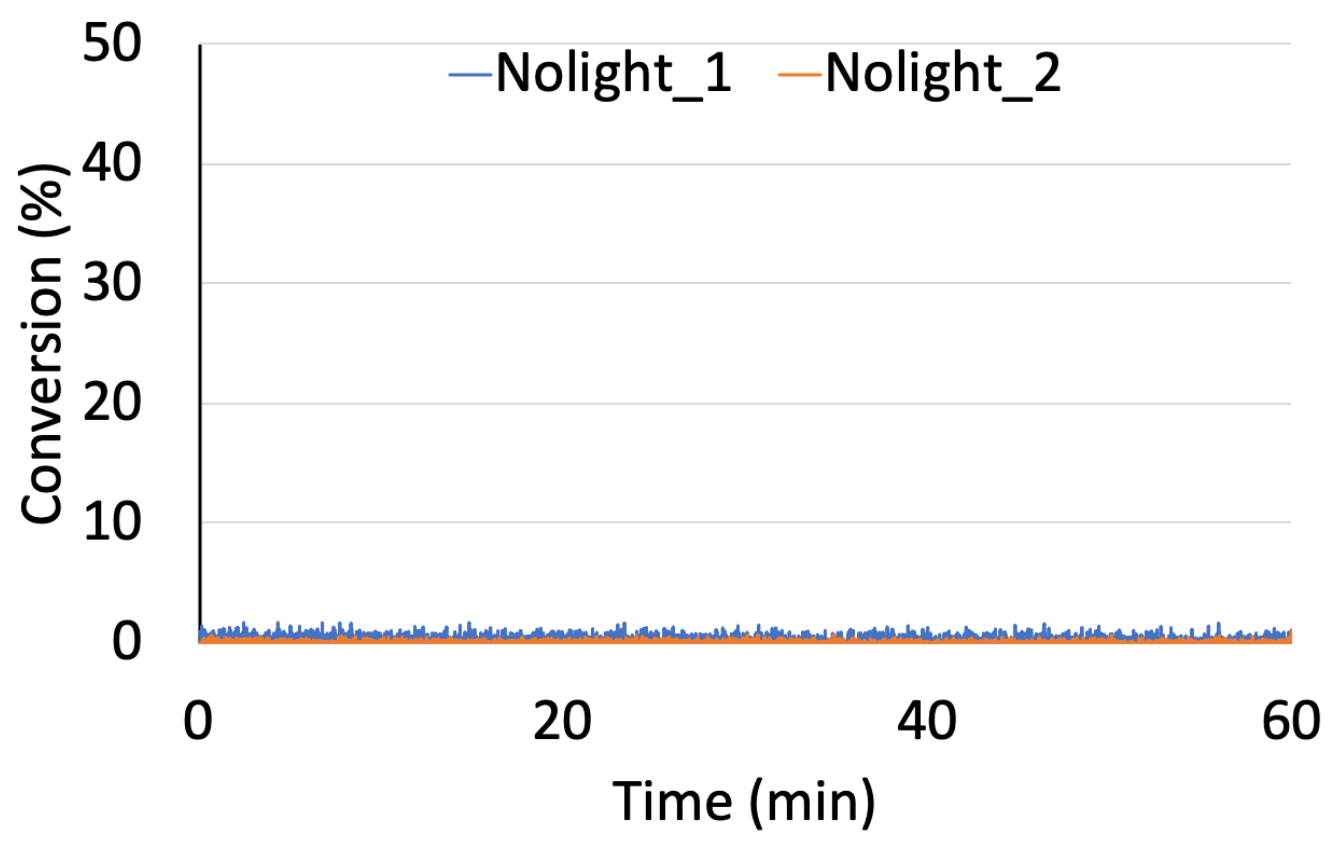

Figure S32. Polymerization profiles of ARC-5,7-diOMe-6-Br with BPO in the absence of light.

\section{References}

1. Stansbury JW, Dickens SH. Determination of double bond conversion in dental resins by near infrared spectroscopy. Dent Mater. 2001;17(1):71-79. doi:10.1016/S01095641(00)00062-2

2. Bernath A, Kärger L, Henning F. Accurate cure modeling for isothermal processing of fast curing epoxy resins. Polymers (Basel). 2016;8(11):1-19. doi:10.3390/polym8110390

3. Stansbury JW, Antonucci JM. Evaluation of methylene lactone monomers in dental resins. Dent Mater. 1992;8(4):270-273. doi:10.1016/0109-5641(92)90098-W

4. Kollár J, Mrlík M, Moravčíková D, et al. Tulips: A Renewable Source of Monomer for Superabsorbent Hydrogels. Macromolecules. 2016;49(11):4047-4056. doi:10.1021/acs.macromol.6b00467

5. Cockburn RA, Siegmann R, Payne KA, Beuermann S, McKenna TFL, Hutchinson RA. 
Free radical copolymerization kinetics of $\gamma$-methyl- $\alpha$-methylene- $\gamma$-butyrolactone (MeMBL). Biomacromolecules. 2011;12(6):2319-2326. doi:10.1021/bm200400s

6. Kim K, Sinha J, Gao G, et al. High-Efficiency Radical Photopolymerization Enhanced by Autonomous Dark Cure. Macromolecules. 2020;53(13):5034-5046.

doi:10.1021/acs.macromol.0c01023

7. Anseth KS, Wang CM, Bowman CN. Reaction behaviour and kinetic constants for photopolymerizations of multi(meth)acrylate monomers. Polymer (Guildf). 1994;35(15):3243-3250. doi:10.1016/0032-3861(94)90129-5 